\title{
Total Absence of Dystrophin Expression Exacerbates Ectopic Myofiber Calcification and Fibrosis and Alters Macrophage Infiltration Patterns

Christopher N.J. Young, ${ }^{* \dagger}$ Maxime R.F. Gosselin, ${ }^{\star}$ Robin Rumney, ${ }^{*}$ Aleksandra Oksiejuk, ${ }^{\star \ddagger}$ Natalia Chira, ${ }^{*}$ Lukasz Bozycki, Paweł Matryba, ${ }^{9 \|}$ Kacper Łukasiewicz, ${ }^{* *}$ Alex P. Kao, ${ }^{\dagger \dagger}$ Joseph Dunlop, ${ }^{\ddagger}$ Samuel C. Robson, ${ }^{* \S \S}$ Krzysztof Zabłocki, ${ }^{\ddagger}$ and Dariusz C. Górecki*ศศा

From the Laboratory of Molecular Medicine,* School of Pharmacy and Biomedical Sciences, the Schools of Mechanical and Design Engineering ${ }^{\dagger \dagger}$ and the Department of Earth and Environmental Sciences, ${ }^{\ddagger \ddagger}$ and the Centre for Enzyme Innovation, ${ }^{\S \S}$ University of Portsmouth, Portsmouth, United Kingdom; the Leicester School of Allied Health Sciences, ${ }^{\dagger}$ De Montfort University, Leicester, United Kingdom; the Laboratory of Cellular Metabolism, ${ }^{\ddagger}$ Department of Biochemistry, and the Laboratories of Biochemistry of Lipids, ${ }^{\S}$ Neurobiology, ${ }^{\top}$ and Molecular Basis of Behavior, ** Nencki Institute of Experimental Biology, Warsaw, Poland; the Department of Immunology, "Medical University of Warsaw, Poland; and the Military Institute of Hygiene and Epidemiology, ${ }^{\mathbf{9}}$ Warsaw, Poland

Accepted for publication September 26, 2019.

Address correspondence to Dariusz C. Górecki, M.D., Ph.D., Molecular Medicine, School of Pharmacy and Biomedical Sciences, University of Portsmouth, White Swan Road, Portsmouth PO1 2DT, United Kingdom. E-mail: darek.gorecki@port.ac.uk.

\begin{abstract}
Duchenne muscular dystrophy (DMD) causes severe disability and death of young men because of progressive muscle degeneration aggravated by sterile inflammation. DMD is also associated with cognitive and bone-function impairments. This complex phenotype results from the cumulative loss of a spectrum of dystrophin isoforms expressed from the largest human gene. Although there is evidence for the loss of shorter isoforms having impact in the central nervous system, their role in muscle is unclear. We found that at 8 weeks, the active phase of pathology in dystrophic mice, dystrophin-null mice $\left(m d x^{\beta g e o}\right)$ presented with a mildly exacerbated phenotype but without an earlier onset, increased serum creatine kinase levels, or decreased muscle strength. However, at 12 months, $m d x^{\beta g e o}$ diaphragm strength was lower, whereas fibrosis increased, compared with $m d x$. The most striking features of the dystrophin-null phenotype were increased ectopic myofiber calcification and altered macrophage infiltration patterns, particularly the close association of macrophages with calcified fibers. Ectopic calcification had the same temporal pattern of presentation and resolution in $m d x^{\beta g e o}$ and $m d x$ muscles, despite significant intensity differences across muscle groups. Comparison of the rare dystrophin-null patients against those with mutations affecting full-length dystrophins may provide mechanistic insights for developing more effective treatments for DMD. (Am J Pathol 2020, 190: 190-205; https:// doi.org/10.1016/j.ajpath.2019.09.021)
\end{abstract}

Duchenne muscular dystrophy (DMD) is a severely debilitating and invariably fatal X-linked neuromuscular disorder, which results from mutations in the $D M D$ gene. ${ }^{1} D M D$ is the largest human gene known, encoding multiple structurally diverse isoforms of dystrophin. ${ }^{2}$ Three full-length transcripts, comprising 79 exons, encode $427-\mathrm{kDa}$ proteins while further intragenic promoters ${ }^{3}$ drive expression of progressively truncated variants (Figure 1A).

The current central hypothesis states that Duchenne muscular dystrophy pathology is caused by the loss of the full-length dystrophin (Dp427) in myofibers, where it anchors the dystrophin-associated protein complex, linking the
Supported by the University of Portsmouth Research and Innovation Development Fund (D.C.G.); US Muscular Dystrophy Association grant MDA294571 (D.C.G.); Polish Ministry of National Defense project Kościuszko grant 523/2017/DA (D.C.G.); a Vice-Chancellor's Early Career Fellowship, De Montfort University (Leicester, UK) (C.Y.); the National
Science Centre (Poland) grants 2016/23/N/NZ4/03313 (L.B.), 2018/28/T/ NZ4/00012 (L.B.), and 2018/29/B/NZ4/02440 (K.Z.); Polish Ministry of Science and Higher Education grant DI2016 007446 (P.M.); and in part by an Expanding Excellence in England (E3) grant from Research England (S.C.R.). Disclosures: None declared. 
extracellular matrix, the sarcolemma, and the intracellular cytoskeleton. This assembly is considered critical for muscle function and survival. Therefore, all the current preclinical and clinical therapeutic approaches are aimed at dystrophin restoration in differentiated muscle cells.

However, there is growing evidence that DMD mutations produce a range of significant cell-autonomous abnormalities in both human and mouse myogenic cells, suggesting a much earlier onset of pathology and explaining impaired muscle regeneration. ${ }^{4-10}$

The severity of DMD-associated cognitive impairment correlates with the cumulative loss of dystrophin isoforms expressed in the central nervous system, thus suggesting a prominent functional role for these shorter isoforms in brain cells. ${ }^{11,12}$ However, little attention has been given to the potential role of shorter dystrophins controlled by the intergenic promoters, and few in-depth comparisons between the full-length and the dystrophin-null muscle phenotypes have been undertaken. Interestingly, the proportion of patients with a severe motor and cognitive phenotype has been shown to correlate with mutations affecting all dystrophins. ${ }^{13}$ Gene mutations causing DMD disrupt the reading frame and include large deletions (68\%), duplications $(11 \%)$, and smaller rearrangements and point mutations (20\%). ${ }^{14}$ Initial analyses indicated that the $D M D$ gene mutation hot spots are located in the regions encoding the full-length isoforms. However, although large deletions and duplications have a nonrandom distribution with the two identifiable hot spots, small insertions/deletions and point mutations are distributed along the entire gene, ${ }^{15}$ thus affecting multiple isoforms.

Interestingly, there are little data documenting the expression of the so-called nonmuscle dystrophin isoforms in muscle. Given that myogenic cells are affected by $D M D$ mutations and are known to express some of these truncated isoforms (eg, Dp71), we hypothesized that null DMD mutations may alter functions of myogenic cells and thus affect the phenotype. Therefore, the consequences of total loss of $D M D$ expression were investigated. The muscle pathology was compared in the most widely used animal model of DMD - the $\mathrm{mdx}$ mouse, lacking full-length isoforms because of a point mutation in exon $23,{ }^{16}$ against the $m d x^{\beta g e o}$ dystrophin-null mouse with the reading-frame disruption downstream of exon 63, which is present in all dystrophins and therefore with all isoforms being ablated. This mouse, unlike models generated by chemical mutagenesis, is a true pan-dystrophin knockout with no revertant fibers present. ${ }^{17}$

\section{Materials and Methods}

\section{Animals}

The male $m d x$ and $m d x^{\beta g e o}$ wild-type control mice (C57B110 and C57B16, respectively) were used in accordance with institutional Ethical Review Board and the Home Office (United Kingdom) approvals. The C57B110 and C57B16 strains derived from the common origin, ${ }^{18}$ and it has been demonstrated that the $\mathrm{mdx}$ mutation on the C57B16 background shows the same pathology as the original B110 strain. ${ }^{19}$ All mice were maintained under pathogen-free conditions and in a controlled environment (12-hour light/dark cycle, $19^{\circ} \mathrm{C}$ to $23^{\circ} \mathrm{C}$ ambient temperature, and $45 \%$ to $65 \%$ humidity). Mice were euthanized by carbon dioxide inhalation, and cells and muscles were dissected and used for protein extraction or frozen in isopentane prechilled in liquid nitrogen for cryosectioning.

\section{Antibodies and Reagents}

The following antibodies were used at 1:1000: antidystrophin (ab15277; Abcam, Cambridge, UK), antiactin (A2066; Sigma-Aldrich, Gillingham, UK), anti-F4/80 (ab6640; Abcam), and anti-CD68 (ab125212; Abcam). All other chemicals were purchased from Sigma-Aldrich or Fisher Scientific (Loughborough, UK).

\section{Serum Creatine Kinase Level Measurement}

Blood samples were collected, allowed to coagulate, and centrifuged for 10 minutes at $2500 \times g$. Sera isolated immediately after centrifugation were analyzed for the creatine kinase levels using the Creatine Kinase Activity Assay Kit (CK-NAC; Randox Laboratories Ltd., Crumlin, UK), according to manufacturer's instructions.

\section{Force Measurements in Diaphragms ex Vivo}

Whole diaphragms from 4-month-old wild-type and dystrophic mice were excised, and contractile force strength was measured following the Treat Neuromuscular Disorders Neuromuscular Network (TREAT-NMD) standard operating procedures (https://treat-nmd.org/researchoverview/preclinical-research/experimental-protocols-fordmd-animal-models, last accessed September 26, 2019) and as previously described. ${ }^{8}$ Essentially, diaphragms were placed into Krebs-Ringer solution. Sutures were tied and muscle then attached to an immobile plastic clamp with the central triangular section of the diaphragm being used for testing. Contractile force was measured using a mechanical force transducer (ADInstruments, Oxford, UK), amplifier, and data acquisition setup. Excitation was achieved via local field potentials through platinum electrodes in oxygenated $\left(95 \% \mathrm{O}_{2}, 5 \% \mathrm{CO}_{2}\right)$ KrebsRinger solution, at a constant temperature $\left(37^{\circ} \mathrm{C}\right)$. After incremental stretching to establish the optimal excitation-to-force generation length and confirmation of the appropriate voltage twitch stimulus, diaphragm sections were subjected to a $140-\mathrm{V}$ (2-millisecond) stimulus train at $100-\mathrm{Hz}$ frequency for 0.5 to 1 second. The test regimen involved collecting six twitch responses, followed by six tetanic trains, with a 2-minute rest 

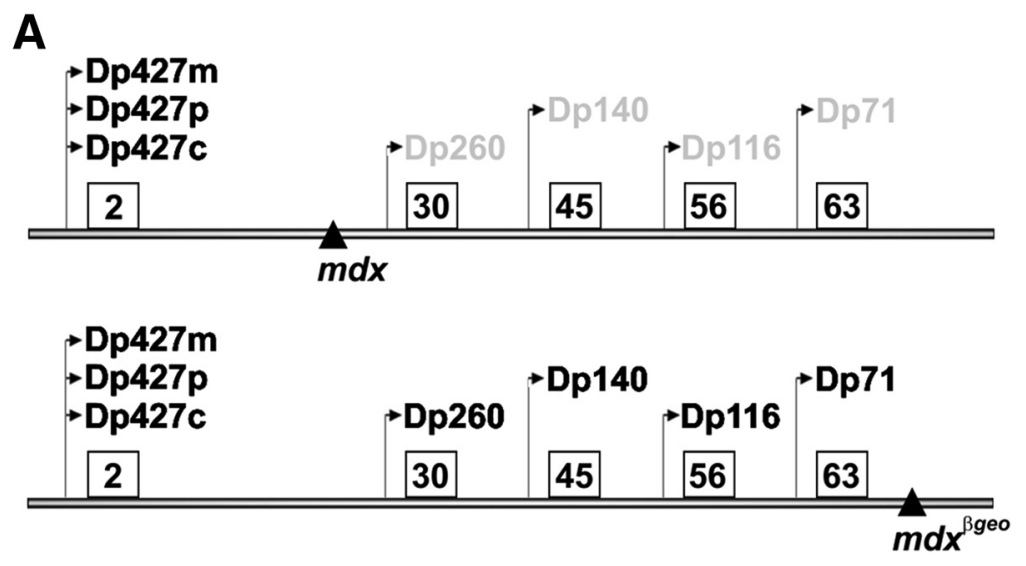

Figure 1 Dystrophin isoform expression in $m d x$ versus $m d x^{\beta g e o}$ muscle. A: DMD mutation location and their effects on predicted isoform expression in $m d x$ and $m d x^{\beta g e o}$. The $\mathrm{mdx}$ mouse carries a point mutation in exon 23, whereas $m d x^{\beta g e o}$ harbors an insertion disrupting the reading frame downstream from exon 63 . B: Western blot analysis of dystrophin protein expression in 8-week muscles showing loss of the Dp427 isoform in $\mathrm{mdx}$ samples and loss of all isoforms from $m d x^{\beta g e o}$, which confirm it to be a complete dystrophin knockout. Triplicate bands shown represent lysates from three different animals, and actin is shown as a protein loading control.

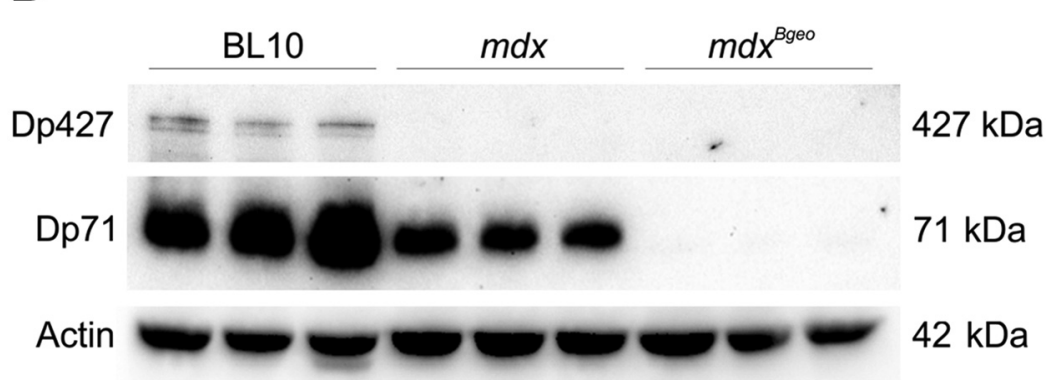

period between each. All forces were normalized to muscle wet weight and expressed as Newtons per gram of tissue (N/g).

\section{Grip Strength Test}

In this and all other in vivo tests, investigators (N.C. and Scott Rodaway) were blinded with respect to the sample group allocation. The grip strength test was performed, as previously described ${ }^{20}$ and according to the TREAT-NMD protocol (http://www.treat-nmd.eu/downloads/file/sops/ sma/SMA_M.2.1.002.pdf, last accessed September 26, 2019). Essentially, mice were held by the tail and slowly approached to a metallic grid $(6 \times 6-\mathrm{cm})$ connected to a force sensor gauge (FG-5000A; Lutron Electronic, London, UK). Once the animal gripped the grid by its forelimbs, a gentle horizontal traction was applied to the tail until the animal let the grid go. The maximal force was recorded over two trials with a 1-minute intertrial interval. Strength was estimated by the mean of both trials.

\section{RNA-Sequencing Analysis}

Total RNA was extracted from tibialis anterior (TA) of 7 week-old C57BL/10 and $m d x$ male mice $(n=4)$, quality controlled, and sequenced, as previously described. ${ }^{8}$

Quality control of raw reads was performed using fastQC version 0.11.7 (Babraham Institute, Cambridge, UK; http:// www.bioinformatics.babraham.ac.uk/projects/fastqc, last accessed September 26, 2019). Reads were trimmed using trim-galore version 0.4.4 (Babraham Institute; https:// www.bioinformatics.babraham.ac.uk/projects/trim_galore, last accessed September 26, 2019) with parameters to remove adapter sequence and low-quality sequence tails. Trimmed reads were mapped against the GRCm38 Mus musculus genome from Ensembl using the STAR version 2. 5.3a modified universal RNA-seq aligner ${ }^{21}$ with the following parameters: -outSAMmultNmax 300 -outSAMstrandField intronMotif. Properly paired reads that mapped uniquely to the genome, with a mapping quality $>20$, were retained for further analyses.

Differential expression analysis was conducted using the DESeq2 package ${ }^{22}$ in R version 3.5.1 (http://www.R-project. org, last accessed September 26, 2019). ${ }^{23}$ Gene models were taken from Ensembl version 91, and read counts over unique genes were quantified using the summarizeOverlaps() function in the GenomicAlignments package ${ }^{24}$ using parameters mode $=$ Union, singleEnd $=$ FALSE, ignore. strand $=$ FALSE, fragments $=$ FALSE, preprocess. reads $=$ invertStrand. $P$ values were adjusted for multiple testing by using the Benjamini and Hochberg false discovery rate correction. ${ }^{25}$ The whole muscle RNA-seq data can be accessed from Array Express (https://www.ebi.ac.uk/ arrayexpress/experiments; accession code E-MTAB-7698).

\section{Histologic Stains}

Hematoxylin and eosin, Alizarin red (AR), periodic acid-Schiff, Von Kossa, oil red $\mathrm{O}$, and picrosirius red 


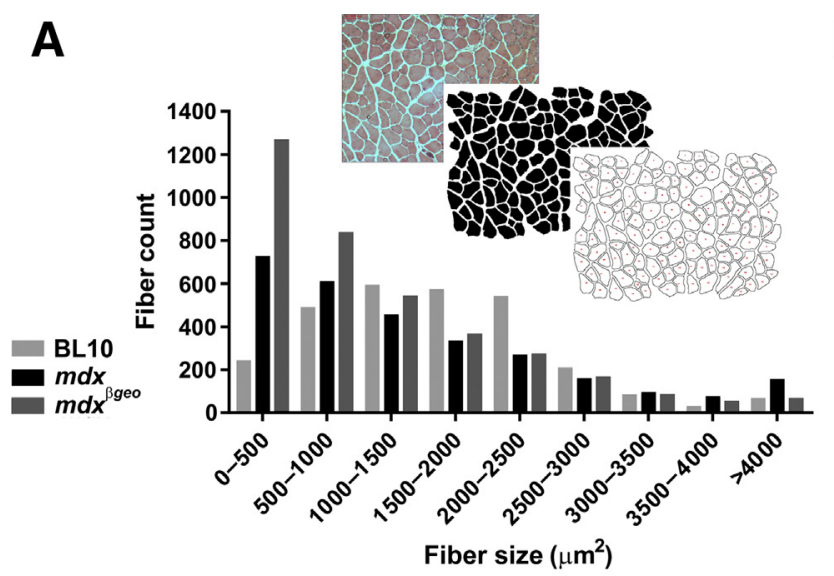

E
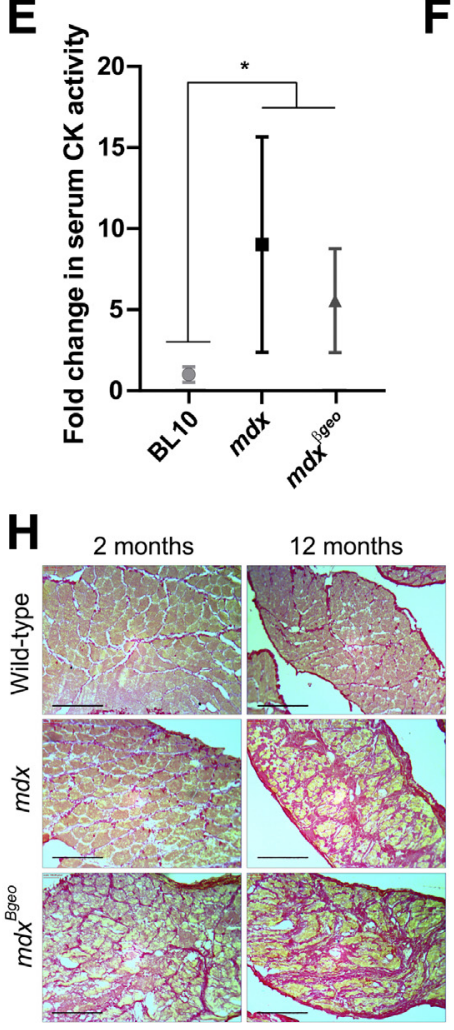

$\mathbf{F}$

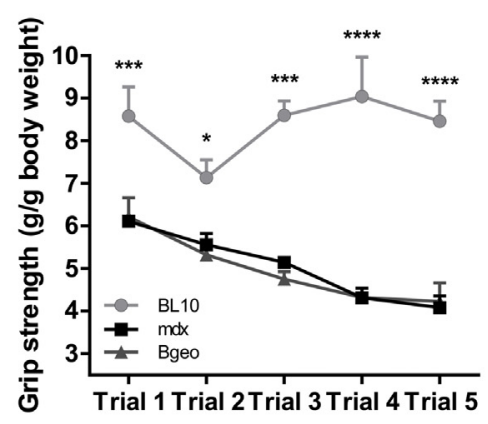

C

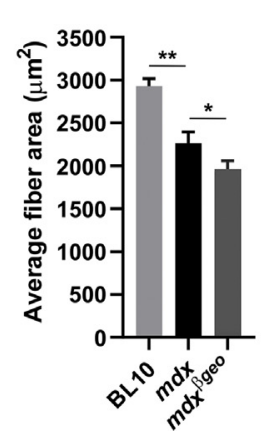

D

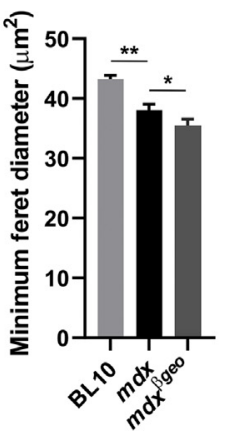

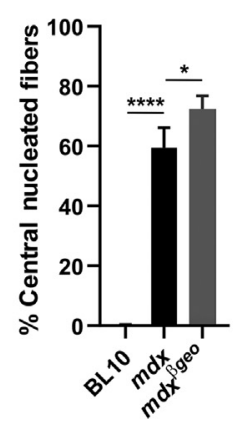

G

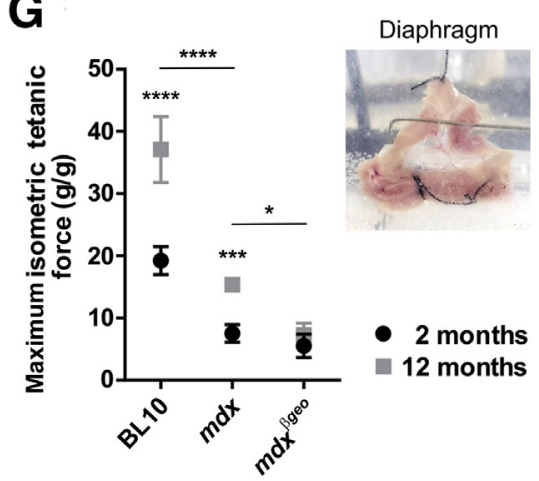

Figure 2 Morphologic and functional alteration in $m d x$ versus $m d x^{\beta g e o}$ muscle. A-C: Morphometric analysis of 8-week tibialis anterior muscles reveals a shift in fiber size (A) in the order of: wild-type (Wt) $>m d x>m d x^{\beta g e o}$, which was found to be consistent for the average fiber area (B) and feret diameter (C). Insets: Example of fiber threshold and the analysis using ImageJ version 2.0.0-rc-69/1.52p (Fiji). D: Numbers of centrally nucleated fibers are significantly elevated: $m d x^{\beta g e o}>m d x>$ Wt. E: Serum creatine kinase (CK) levels indicative of sarcolemma stability are not significantly altered in $m d x^{\beta g e o}$ compared with $m d x$. F: Grip strength at 8 weeks is reduced by approximately $50 \%$ in both $m d x$ and $m d x^{\beta g e o}$ compared with Wt, and diaphragm contractile force is also low in both $m d x$ and $m d x^{\beta g e o}$. G: In contrast, at 12 months, increases in maximum force were recorded in both Wt and $m d x$, but not in $m d x^{\beta g e o}$, diaphragms, which remain at a basal level. $\mathbf{H}$ and $\mathbf{I}$ : Picrosirius red staining for collagen $(\mathbf{H})$ and oil red 0 staining for fat $(\mathbf{I})$ in 8-week versus 12 -month diaphragms reveal significant increases in older animals: $m d x^{\beta g e o}>m d x>$ Wt. Data are expressed as means \pm SD (B-I). $n=3$ to 5 (A-I). ${ }^{*} P<0.05,{ }^{* *} P<0.001$, and ${ }^{* * * * P<0.0001}$. Scale bars $=250 \mu \mathrm{m}(\mathbf{H}$ and $\mathbf{I})$. FOV, field of view.

staining methods followed standard operating procedures from TREAT-NMD-recommended protocols available online (http://treat-nmd.eu/research/preclinical/dmd-sops, last accessed September 26, 2019). All staining was performed using cryosections (10 $\mu \mathrm{m}$ thick), air dried onto poly-L-lysine-coated glass slides (Fisher Scientific). Slides were mounted in DPX or aqueous media, coverslipped, and imaged (Axiozoom V.16; Zeiss, Cambridge, UK). Representative images per genotype are shown, whereas montages, where $n=30$ to 40 , were constructed and assessed using ImageJ version 2.0.0-rc-69/1.52p (Fiji, https://fiji.sc, last accessed September 26, 2019) counting tools. $^{26}$

Whole-Body Tissue Clearing, Imaging, and Analysis

Clearing procedure was performed as described previously. ${ }^{27}$ Briefly, animals were deeply anesthetized with i.p. 


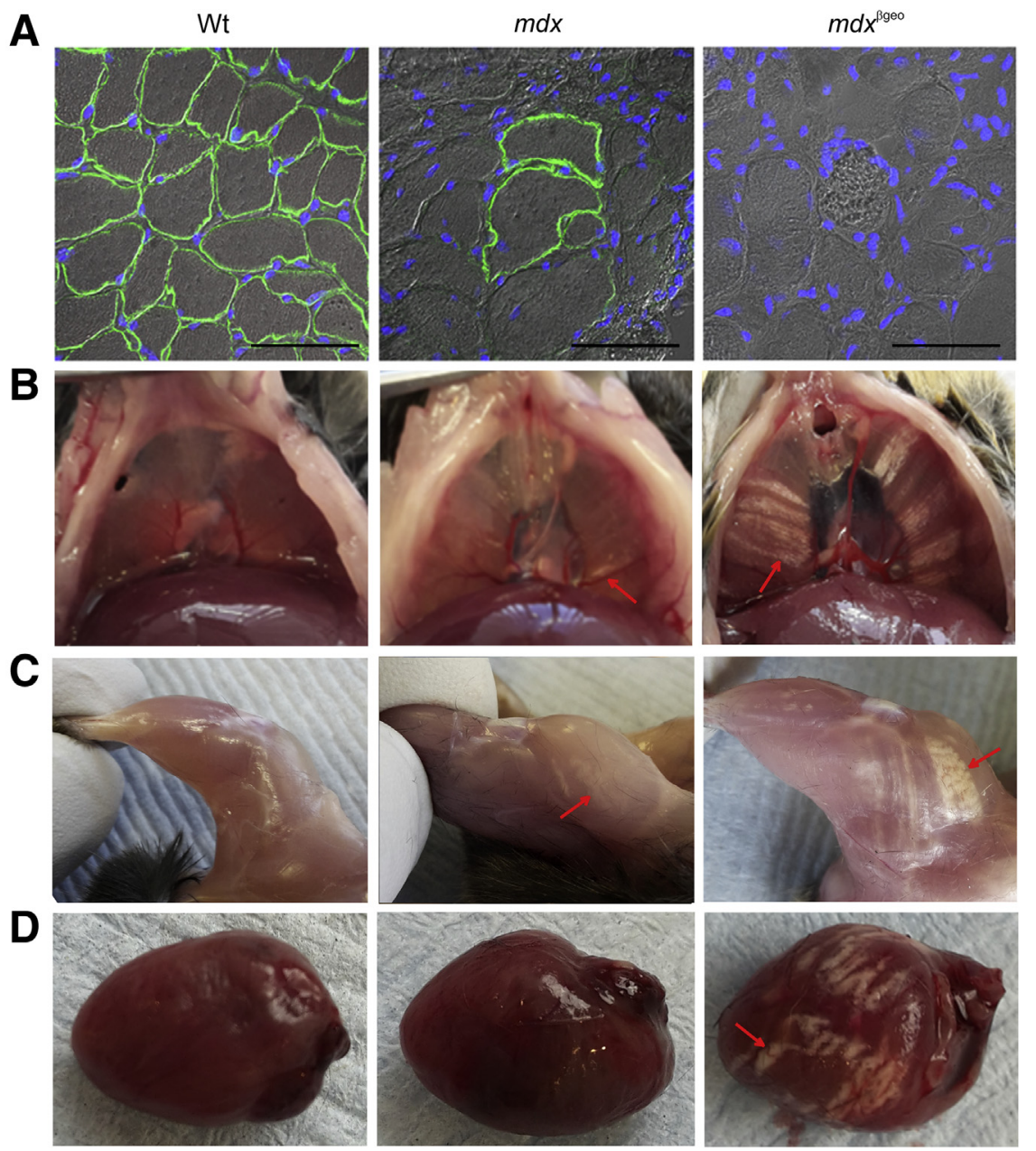

Figure 3 Muscle fiber mineralization is linked to the loss of dystrophin expression in $m d x$ and $m d x^{\beta g e o}$. A: Immunohistochemistry staining for dystrophin in 8-week tibialis anterior (TA) muscle sections confirms the $m d x$ to express dystrophin in a small number of revertant fibers. In contrast, $m d x^{\beta g e o}$ animals display no revertant fibers, in keeping with the molecular alteration in these animals. B: On dissection, significant white striations (arrows) are observed in the diaphragms of $m d x^{\beta g e o}$, which are also found in $m d x$, albeit at much lower levels, but not in controls. Heightened diaphragm hypercontraction is also consistently observed in the order of: $m d x^{\beta g e o}>m d x>$ wildtype $(\mathrm{Wt})$, represented by the enlarged region of translucent connective tissue in the center. C: Striations are found in all skeletal muscle groups of dystrophic mice but at different levels, with proximal muscles (quadriceps and gluteus) being affected more than distal muscles, such as TA. D: Heart muscles are affected, albeit showing slightly different striation patterns than skeletal muscles (Supplemental Figure S1). Arrows highlight regions of ectopic calcification (white streaks). Scale bars $=100 \mu \mathrm{m}(\mathbf{A})$.

injection of lethal dose of sodium pentobarbital (100 mg/ $\mathrm{kg}$ ), subjected to cardiac perfusion, and subjected to fixation followed by 2 to 3 days of clearing with CUBIC reagent- $1^{28}$ or reagent-1A (Riken, http://cubic.riken.jp/data/CUBIC clearing_protocol_with_Reagent-1A.pdf, last accessed September 26, 2019) clearing solutions and 1 day of 0 . $03 \%(\mathrm{w} / \mathrm{v})$ AR staining dissolved in fresh clearing solution. Finally, specimens were placed for 2 to 3 days of gentle shaking with fresh clearing solution at $37^{\circ} \mathrm{C}$ in an incubator to remove the excess of unbound AR. Images were collected with customized light-sheet apparatus and analyzed according to a previously described protocol. $^{27}$

\section{Immunolocalization and Morphologic Analysis}

Frozen muscle was transferred to a cryostat chamber and allowed to equilibrate to $-20^{\circ} \mathrm{C}$. Cryosections $(10 \mu \mathrm{m}$ thick) were then cut from the middle third of the sample and collected on poly-L-lysine $(0.5 \mathrm{mg} / \mathrm{mL})$-coated glass slides. Sections were allowed to air dry for several hours. Samples were fixed in a $2 \%$ to $4 \% \mathrm{w} / \mathrm{v}$ paraformaldehyde solution in Tris-buffered saline/Tween 20 for 15 minutes at $4{ }^{\circ} \mathrm{C}$, followed by two washes in phosphate-buffered saline/Tween 20. The primary antibody incubation in phosphate-buffered saline/Tween 20 containing $10 \% \mathrm{v} / \mathrm{v}$ serum was applied for 2 hours at room temperature or overnight at $4^{\circ} \mathrm{C}$. Three 5 -minute Tris-buffered saline/ Tween 20 washes were applied before secondary antibody incubation in phosphate-buffered saline/Tween 20 and $10 \% \mathrm{v} / \mathrm{v}$ serum containing Hoechst (1:1000) fluorescent nuclear counterstain for 1 hour at room temperature. Sections were finally washed three times for 30 minutes before mounting in FluorSave (Merk Millipore, Watford, UK) fluorescence mounting medium. Either entire crosssections through the midportion of TA muscles were captured in their entirety using Axiozoom V.16 (Zeiss) or whole cross-sections were made of montaged $\times 20$ magnification fields of view. For quantification of immunofluorescence cells, a semiautomated (unbiased) method using a thresholding macro designed in ImageJ software (Fiji) was used. Numbers were then expressed per unit of area. For diaphragms, counts per unit area for each animal were derived by averaging the counts from five fields of view encompassing a significant portion of each diaphragm cross-section. Counts were also made 

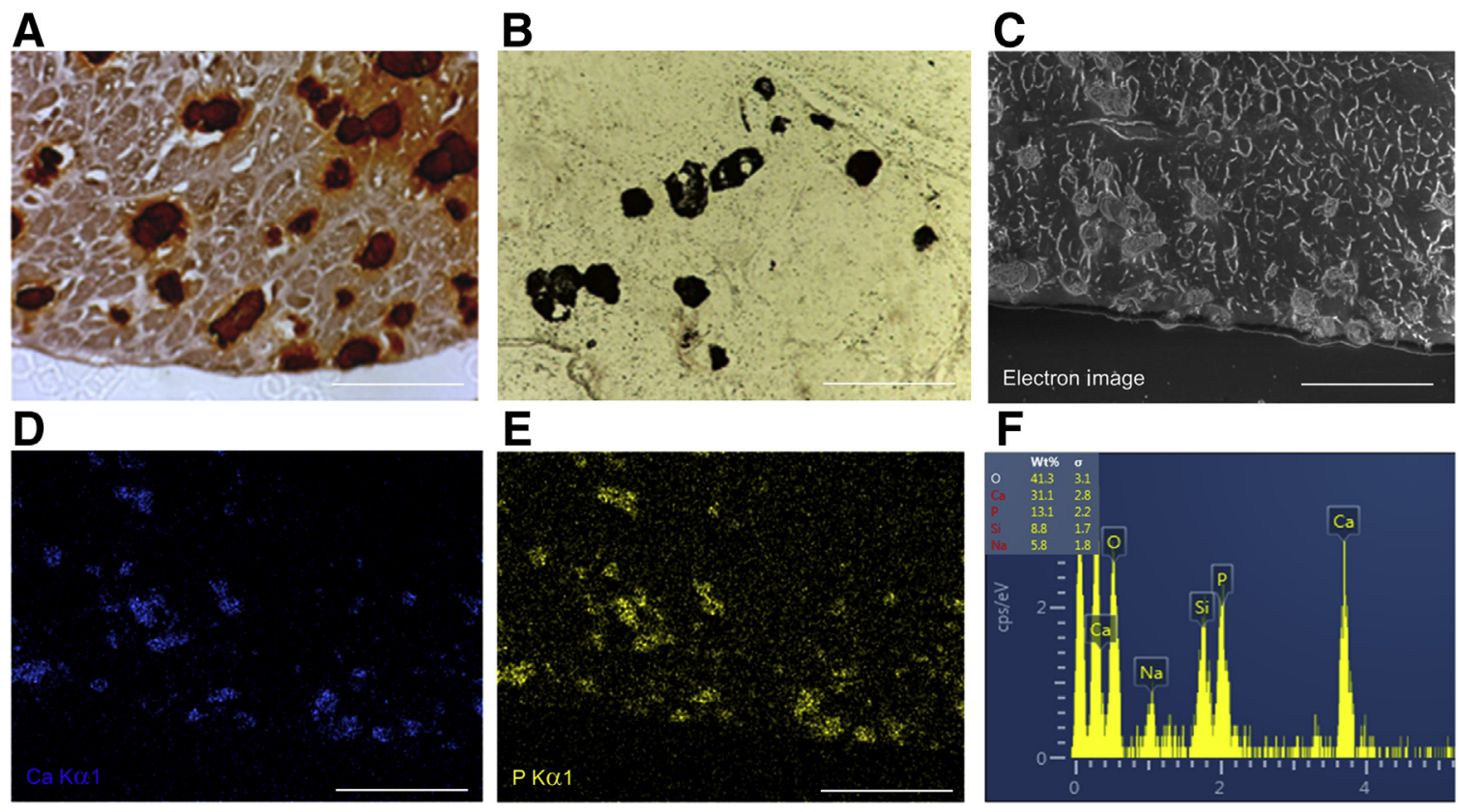

Figure 4 Histochemical and mineral analyses in 8-week-old $m d x$ and $m d x^{\beta g e o}$ muscles. A and B: Alizarin red (A) and Von Kossa (B) staining demonstrates that the white striations in diaphragm sections contain calcium and phosphate, respectively. C-F: Electron backscatter diffraction analysis of diaphragm sections from 8-week $m d x^{\beta g e o}$ (C) identifies colocalization of calcium (D) and phosphate (E) in electron-dense fibers, with the calcium/phosphate ratio of 1.50 $(\mathbf{F})$, consistent with the presence of tricalcium phosphate $\left[\mathrm{Ca}_{3}\left(\mathrm{PO}_{4}\right)_{2}\right]$ or hydroxyapatite, which has a ratio of 1.6729. $n=3$ mice $(\mathbf{A}-\mathbf{F})$. Scale bars $=250 \mu \mathrm{m}$ $(\mathrm{A}-\mathrm{E})$.

using the threshold and analyze particles functions of ImageJ software.

\section{Western Blot Analysis}

Proteins were extracted, resolved, and blotted, as described previously. ${ }^{20,29}$ Blots were blocked in $5 \% \mathrm{w} / \mathrm{v}$ nonfat milk powder in $1 \times$ Tris-buffered saline $(50 \mathrm{mmol} / \mathrm{L}$ Tris, 150 $\mathrm{mmol} / \mathrm{L} \mathrm{NaCl}$, and $0.01 \%$ v/v Tween-20; Sigma-Aldrich), for 1 hour before probing with primary antibody diluted in the same blocking buffer (overnight at $4^{\circ} \mathrm{C}$ or 2 hours at room temperature), then washed (three times) with $1 \times$ Trisbuffered saline/Tween 20 for 10 minutes and incubated with the appropriate horseradish peroxidase-conjugated secondary antibody: anti-mouse 1:10:000 (A4416; SigmaAldrich) or anti-rabbit 1:5000 (A6154; Sigma-Aldrich) overnight at $4^{\circ} \mathrm{C}$ or 1 hour at room temperature. Specific protein bands were visualized using Luminata Classico or Forte chemiluminescent substrates (WBLUC0500 or WBLUF0500, respectively; Merck Millipore), and images were obtained using a ChemiDoc MP system (Bio-Rad, Hertfordshire, UK). Densitometric analyses were performed using the integrated density measurement function of ImageJ software. All experiments were repeated at least three times in triplicate, throughout.

\section{X-Ray Micro-Computed Tomography}

Quadriceps were placed within a 1.5-mL tube (Eppendorf, Stevenage, UK) and supported by a polyurethane foam saturated in $70 \%$ ethanol. Muscles were imaged using a Zeiss Xradia 520 Versa X-ray microscope (Zeiss) operating at an energy of $50 \mathrm{kV}$, a power of $4 \mathrm{~W}$, and a tube current of $80 \mu \mathrm{A}$; and a Zeiss LE1 filter was positioned directly after the X-ray source. A $0.4 \times$ objective lens was used with an $\mathrm{X}$-ray source (sample distance of $20 \mathrm{~mm}$ ) and a detector (sample distance of $105 \mathrm{~mm}$ ). A total of $1601 \mathrm{X}$-ray projection images were collected over 360 degrees at equal intervals with an isotropic voxel size of $11 \mu \mathrm{m}$. The exposure time for each projection was 2 seconds. The projections were reconstructed using the manufacturer's integrated software, which uses a filtered back projection reconstruction algorithm. The individual tomography scans were quantified using the threshold function in Image $^{26}$ and visualized in three dimensions using TXM3DViewer (Zeiss).

\section{Statistical Analysis}

Results are reported as means $\pm \mathrm{SD}$, where $n$ refers to number of independent experiments (3 to 6). Significance scores were based on Kruskal-Wallis with post-hoc Dunn's test for nonparametric multiple comparisons; one-way analysis of variance with post-hoc Tukey test for normal multiple comparisons; and unpaired $t$-tests for individual comparisons, with Mann-Whitney post-hoc test for nonparametric $t$-tests (GraphPad Prism8; GraphPad Software, San Diego, CA). For cumulative frequency distribution, Kolmogorov-Smirnov test was used. Differences were considered statistically significant at $P<0.05$. 


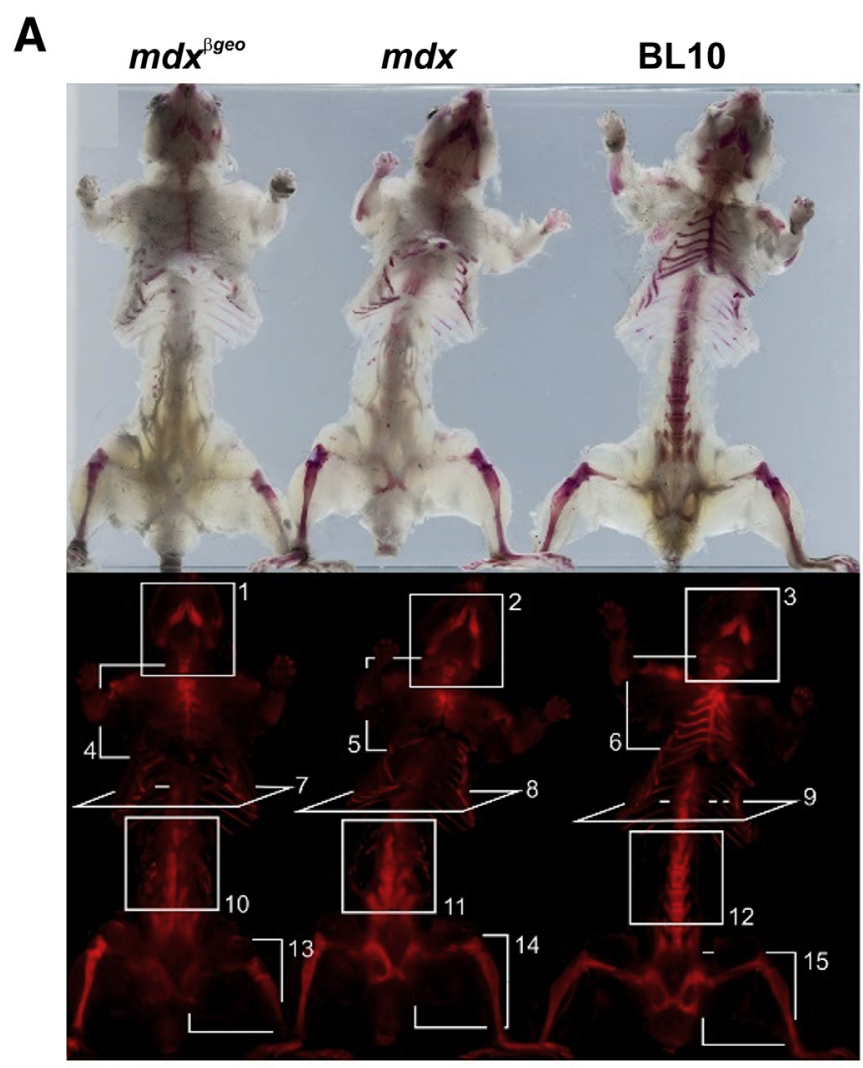

B
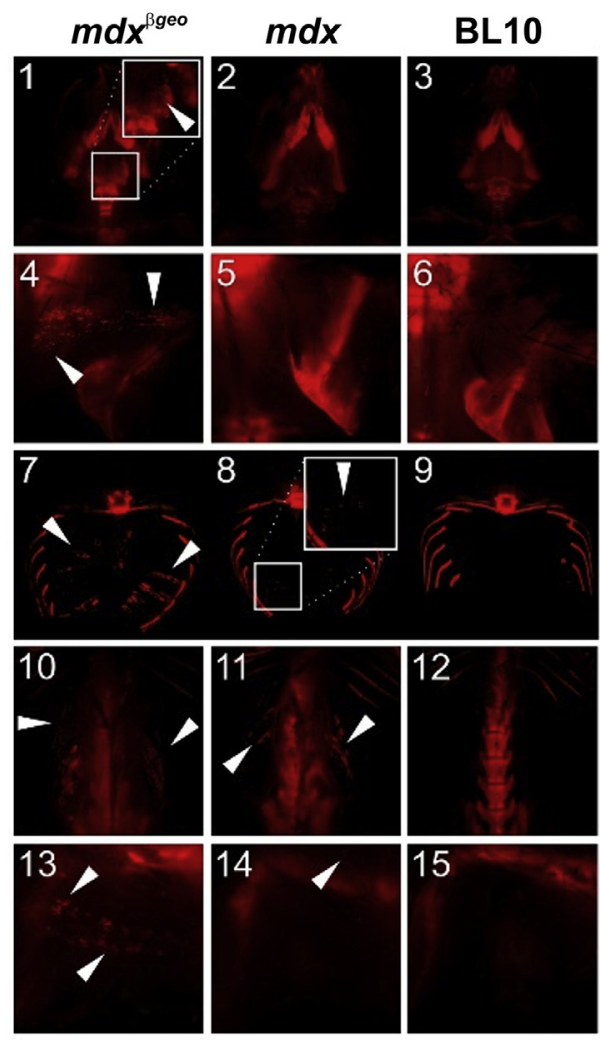

C
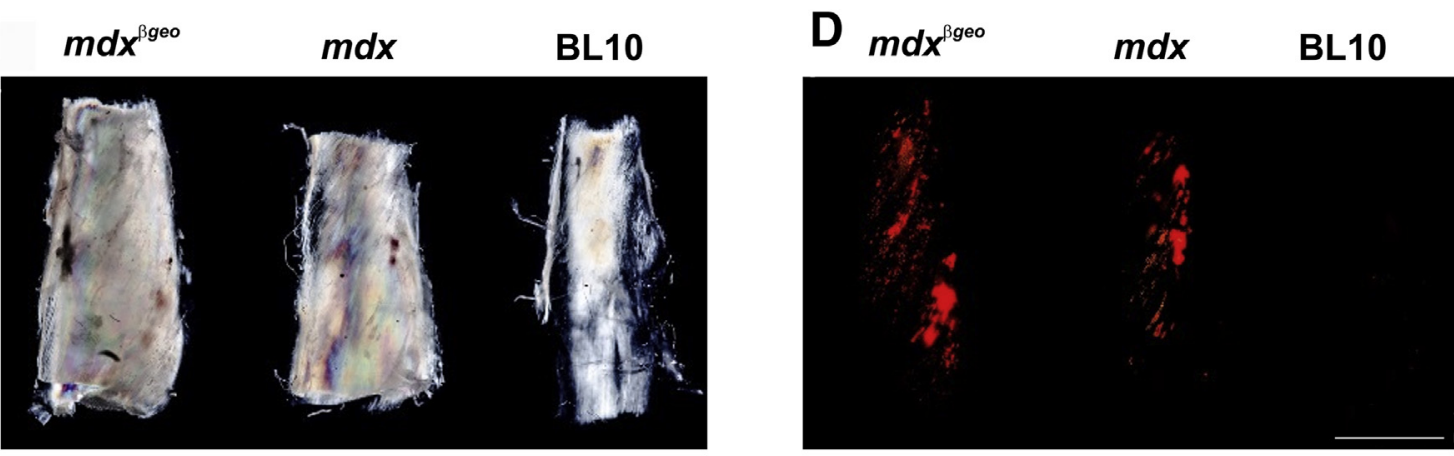

$\mathbf{E}$
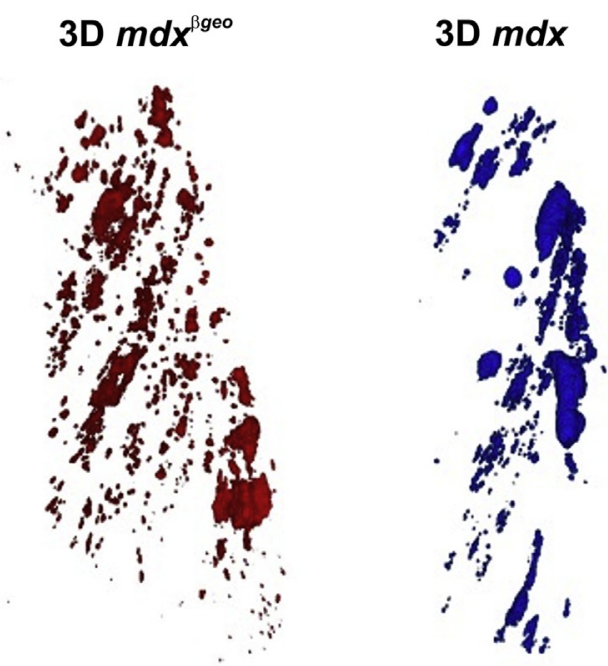

$\mathbf{F}$

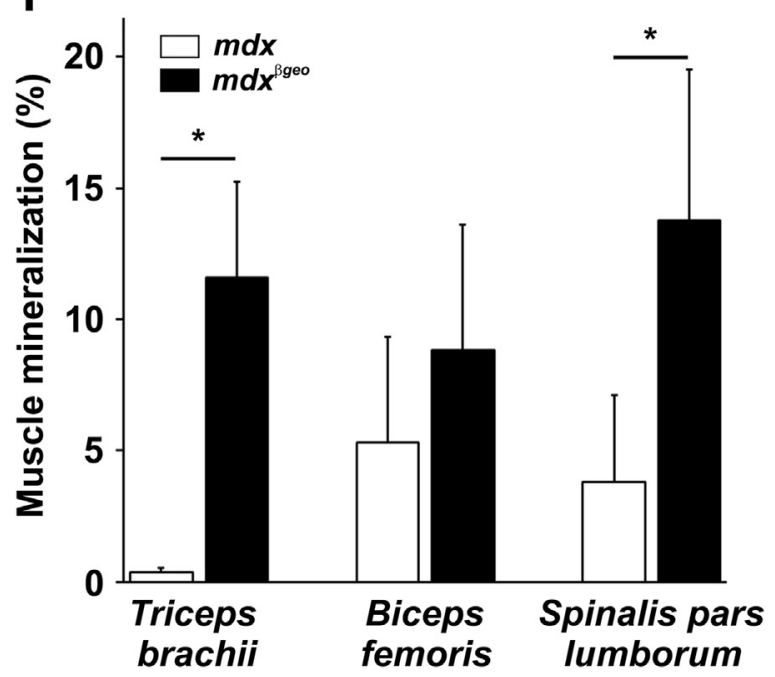




\section{Results}

\section{Dystrophic Pathology in $m d x^{\beta g e o}$ Dystrophin-Null Mice}

Muscle pathology in the $m d x$ muscles begins to present at 2 to 3 weeks, reaching maximum intensity in leg muscles at approximately 8 weeks, before plateauing at approximately 12 to 16 weeks. ${ }^{30,31}$ However, the mdx mouse diaphragm shows progressive pathology ${ }^{32}$ and, therefore, this muscle closely represents the human condition.

To identify the potential phenotypic differences resulting from the absence of all versus full-length isoforms, $m d x$ and $m d x^{\beta g e o}$ (dystrophin-null) mice (Figure 1) were compared following the TREAT-NMD standard operating procedures. $^{33,34}$

At 8 weeks (the peak of pathology), morphologic analysis of leg muscles revealed a significant shift in myofiber crosssectional area toward smaller fibers in dystrophic muscle in the order of wild-type (BL10) $>m d x>m d x^{\beta g e o}$ (Figure 2, A and B). A significant reduction in the average ferret diameter followed the same trend (Kruskal-Wallis with Dunn's test) (Figure 2C). Central nucleation was significantly elevated in $m d x^{\beta g e o}$ compared with $m d x$ (Mann-Whitney test, $P=0.0159$ ) (Figure 2D). At 8 weeks, serum creatine kinase levels (Figure 2E) were not significantly different (MannWhitney test, $P=0.4127$ ) between the two dystrophic strains, indicating that loss of short dystrophins did not exacerbate sarcolemma damage. Grip strength in vivo (Figure $2 \mathrm{~F}$ ) and diaphragm strength ex vivo (Figure 2G) were equally reduced in both dystrophic strains at 8 weeks. Yet, there was an age-dependent difference between $m d x^{\beta g e o}$ and $m d x$ : In 12-month-old animals, diaphragm contractile force strength showed small but significant increase in $m d x$ preparations (unpaired $t$-test, $\mathrm{t}=6.572, \mathrm{df}=4, P=0.0028$ ), but no increase was found in $m d x^{\beta g e o}$ (unpaired $t$-test, $\mathrm{t}=0.6558$, $\mathrm{df}=4, P=0.5478$ ) (Figure $2 \mathrm{G}$ ). Furthermore, fibrosis (Figure $2 \mathrm{H}$ ) and fat accumulations (Figure 2I) were both found elevated in 12-month-old $m d x^{\beta g e o}$ diaphragms compared with age-matched $m d x$.

\section{Total Dystrophin Loss Exacerbates Ectopic Calcification of Dystrophic Muscle Fibers}

Muscles from $m d x^{\beta g e o}$ mice do not express any dystrophin isoforms (Figure 1B) or truncated variants in revertant fibers (Figure 3A). In contrast, at 8 weeks, striking opaque fibers, particularly prominent in diaphragms but detectable in all major skeletal muscle groups, were found to be notably more abundant in $m d x^{\beta g e o}$ than in $m d x$ mice (Figure 3, B-D). The appearance of these fibers closely resembled ectopic calcification reported previously in the $m d x, m d x /$ Utrophin double knockout and the humanized- $m d x$ mouse models ${ }^{35-38}$ in the golden retriever muscular dystrophy dog, ${ }^{39,40}$ and, more important, in DMD patients. ${ }^{41}$ To confirm, it was first verified if calcium- and phosphoruscontaining deposits were present in these opaque diaphragm fibers using AR (Figure 4A) and Von Kossa (Figure 4B) stains, respectively. Scanning electron microscopy energy-dispersive X-ray spectroscopy electron backscatter analysis (Figure 4C) confirmed the presence of mineral deposits containing both calcium (Figure 4D) and phosphate (Figure 4E) with a molar ratio of 3:2 (Figure 4F), consistent with tricalcium phosphate $\left[\mathrm{Ca}_{3}\left(\mathrm{PO}_{4}\right)_{2}\right] .{ }^{42}$

The striated appearance of calcified fibers showed regions of calcification with distinct patterning, sometimes along the length of almost entire fiber, sometimes in short regions of otherwise unaltered fiber (Figure 3C and Supplemental Video S1). Muscle groups most severely affected with ectopic calcification were diaphragm (Figure 3B) and the proximal limb (quadriceps and gluteus) with a consistently milder phenotype in the distal groups (TA and gastrocnemius) (Figure 3C). More important, this ectopic calcification was also found in cardiac muscles of $m d x^{\beta g e o}$ (Figure 3D and Supplemental Figure S1), which, to our knowledge, is the first demonstration of this abnormality in a DMD model.

\section{Whole-Body Musculature Analysis of Ectopic Calcification in $m d x$ and $m d x^{\beta g e o}$}

The initial study revealed significant differences in ectopic calcifications between various muscle groups, indicating the need for systematic comparisons. To screen for and quantify ectopic mineralization in various muscle groups of the entire animal, previously optimized whole-body tissue optical clearing method ${ }^{27}$ was applied. Such an approach, when combined with AR staining, allowed us to demonstrate excessive accumulation of ectopic calcifications in $m d x^{\beta g e o}$ versus $m d x$ and confirm complete absence of these in control animals (Figure 5, A-D). Thereby, calcified deposits were observed particularly abundant within $m d x^{\beta g e o}$ diaphragms (Figure 5B) but also in skeletal muscles of the laryngopharynx, forelimb, lumbar region, pelvic region, and

\footnotetext{
Figure 5 Whole-body and three-dimensional muscle analysis of ectopic calcifications in $m d x$ and $m d x^{\beta g e o}$. Whole-body tissue clearing and Alizarin red staining show distribution of ectopic calcification across the entire musculature. A: Representative bright-field (top panels) and epifluorescent images (bottom panels) reveal sites of myofiber calcification and allow detailed comparative imaging of the affected body regions. B: Epifluorescent images of the selected planes from A demonstrate higher prevalence of calcifications in $m d x^{\beta g e o}$ versus $m d x$ with a complete absence of deposits in the control mouse. Arrowheads indicate clusters of calcium deposits in laryngopharynx (1 to 3), forelimb (4 to 6), diaphragm (7 to 9), lumbar region (10 to 12 ), and hind limb (13 to 15). C and D: Spinalis pars lumborum from macroscopically prescreened mice was isolated and imaged in crossed polarized light (C) and light-sheet fluorescence microscopy (D). E and F: Three-dimensional light-sheet data allow us to reconstruct distribution of sites of ectopic calcification (E) and quantify its pattern in muscles of $m d x^{\beta g e o}$ and $m d x$ - presented herein as percentage mineralization and cumulative frequency distributions in triceps brachii, spinalis pars lumborum, and biceps femoris (F). Unpaired $t$-test and two-sample Kolmogorov-Smirnov test were performed. Data are expressed as means \pm SD (F). $n=3$ mice per group (F). ${ }^{*} P<0.05$. Scale bar $=5 \mathrm{~mm}(\mathbf{D})$. Original magnification, $\times 4(\mathbf{A}-\mathbf{E})$.
} 

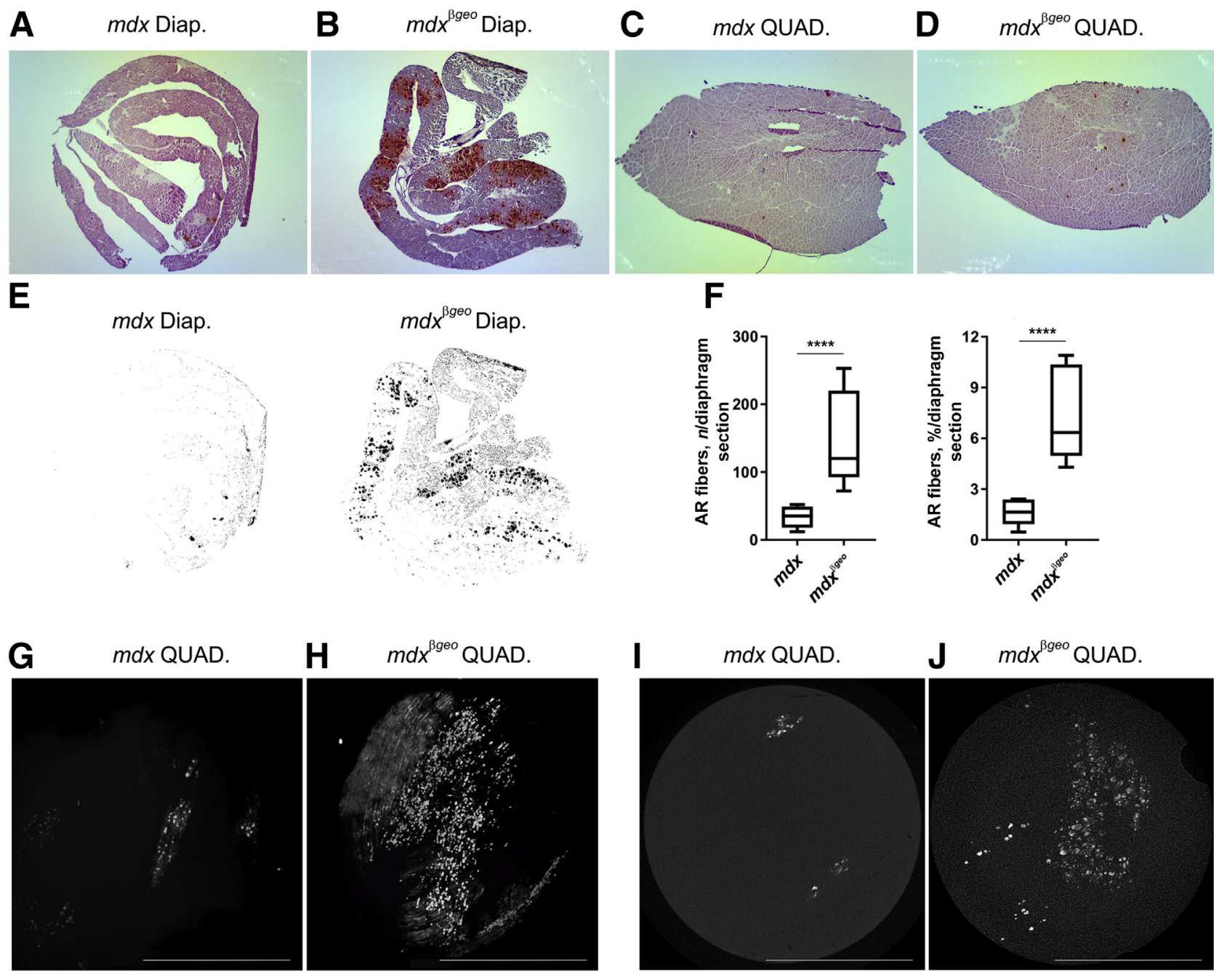

Figure 6 Quantification of muscle fiber mineralization in $m d x$ versus $m d x^{\beta g e o}$. A and B: Alizarin red (AR) staining was quantified in $m d x(\mathbf{A})$ and $m d x^{\beta g e o}$ (B) diaphragms (Diap.) at 8 weeks of age. $\mathbf{C}$ and $\mathbf{D}$ : Representative images of tibialis anterior sections from $m d x(\mathbf{C})$ and $m d x^{\beta g e o}$ (D) are shown to illustrate the difference in severity between different muscle groups. E: Alizarin red images were thresholded, a mask was generated in ImageJ software, and fibers displaying an arbitrarily assigned positive value at or above the threshold level were counted using the ImageJ version 2.0.0-rc-69/1.52p (Fiji) particle analysis function. F: A significant increase in absolute numbers and percentage of mineralized muscle fibers is found in $m d x^{\beta g e o}$ compared with age-matched $m d x$ diaphragms. G-J: Striations along the entire length of fibers were analyzed in whole muscle mineralization analysis using three-dimensional (3D) $X$-ray imaging. $\mathbf{G}$ and $\mathbf{H}$ : Quadriceps (QUAD.) from 8-week-old $m d x(\mathbf{G})$ and $m d x^{\beta g e o}(\mathbf{H})$ in 3D rendering reveals two different patterns of mineralization: one diffuse and globular and the other striated (left and right sides of tissue shown in $\mathbf{H}$, respectively). I and J: Representative Z-sections for $m d x$ and $m d x^{\beta g e o}$ are shown, respectively. Data are expressed as means \pm SD (F). $n=3(\mathbf{F}) .{ }^{* * * * P}<0.0001$. Scale bars $=5 \mathrm{~mm}(\mathbf{G}-\mathbf{J})$. Original magnification, $\times 4(\mathbf{A}-\mathbf{E})$.

hind limbs. Next, a customized light-sheet setup was used to perform detailed three-dimensional imaging of isolated muscles from three distinct body regions (ie, spinalis pars lumborum, biceps femoris, and triceps brachii) (Figure 5, E and F). When compared with $m d x$, every $m d x^{\beta g e o}$ muscle was characterized by a higher percentage of tissue mineralization, with differences being particularly striking in triceps brachii, where ectopic calcification reached $11.59 \%$ in $m d x^{\beta g e o}$ and $0.36 \%$ in $m d x$ [percentage of mineralization: unpaired $t$-test $\mathrm{t}(4)=5.32 ; P<0.01]$ (Figure 5F). In contrast, the difference was not found to be statistically significant in spinalis pars lumborum [unpaired $t$-test $\mathrm{t}(4)=2.62 ; P=0.058$ ] (Figure 5F) and biceps femoris [unpaired $t$-test $\mathrm{t}(4)=0.97 ; P=0.386$ ] (Figure 5F). $\mathrm{Cu}$ mulative frequency distribution analysis showed different distribution of calcified deposits in triceps brachii and spinalis pars lumborum muscles from $m d x^{\beta g e o}$ mice in comparison to $m d x$ mice (Figure $5 \mathrm{~F}$ ).

Further confirmation of muscle fiber calcification was undertaken using AR staining of TA (Figure 6, C and D) and diaphragm (Figure 6, A and B) sections and particle analysis-based quantification of threshold images using ImageJ software (Figure 6E). Significantly elevated numbers and percentages of calcified fibers were confirmed in diaphragms (Figure 6F), whereas TA was confirmed to be less affected by the ectopic calcification. Finally, ectopic calcification in isolated 8-week-old quadriceps $m d x$ and $m d x^{\beta g e o}$ muscles were visualized in three dimensions under the X-ray microscope (Xradia; Zeiss) (Figure 6, G-J, and Supplemental Video S1). 


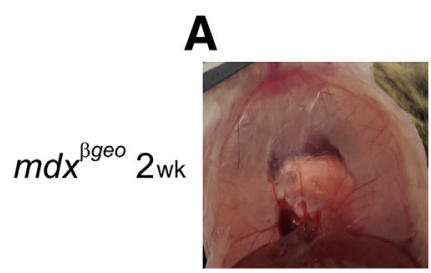

B

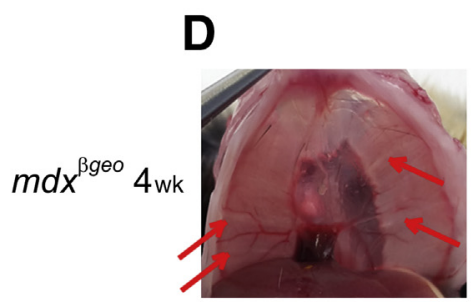

E

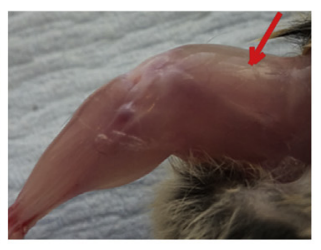

$\mathbf{F}$
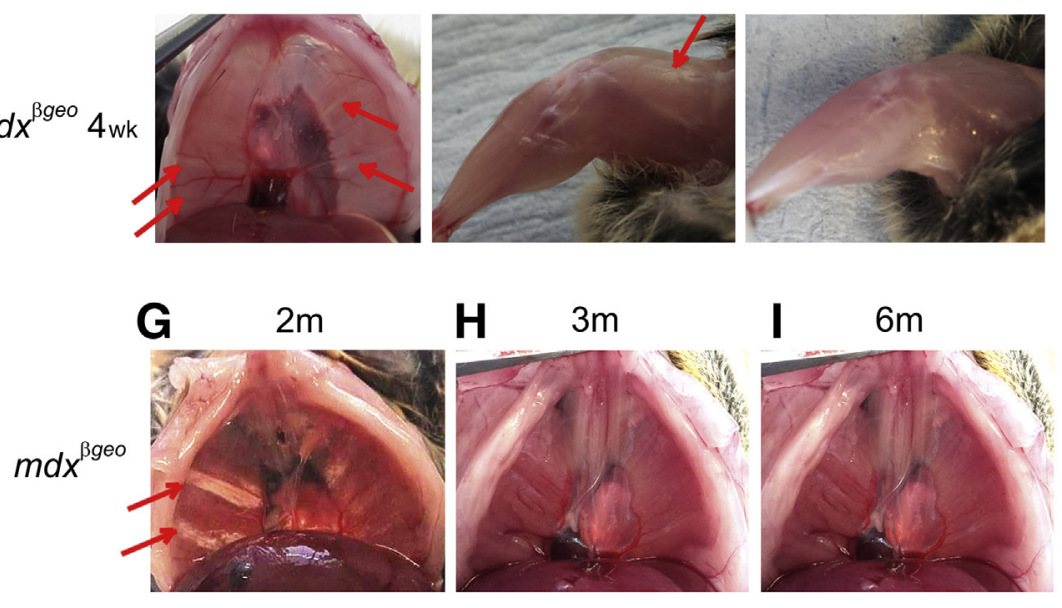

\section{$\mathrm{J}$}

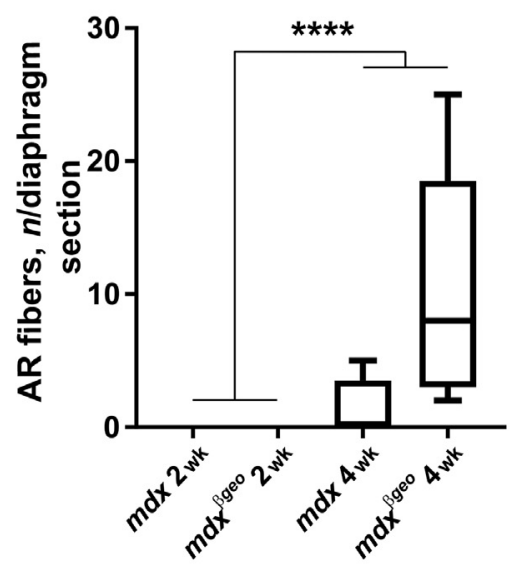

K

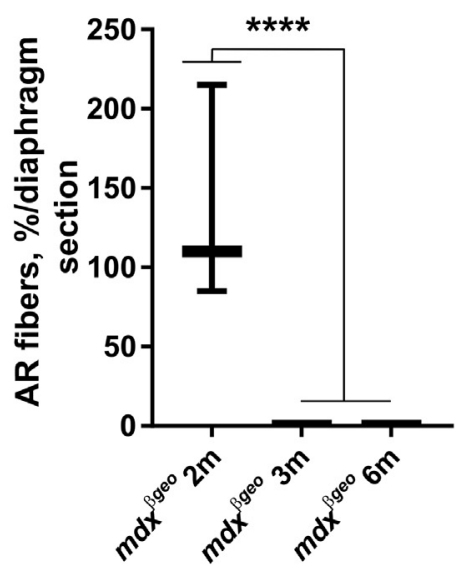

Figure 7 Timing and evolution of muscle fiber mineralization in $m d x^{\beta g e o}$ muscles. A-C: At 2 weeks, muscles appear normal with no visible striations. D-F: By 4 weeks, light striations begin to appear (arrows). G-I: After a peak at approximately 2 months (G), calcium-containing fibers (arrows) disappear at approximately 10 to 12 weeks $(\mathbf{H})$, and are replaced by connective tissue (I). Note the increased opacity of the diaphragm with increasing age (G to I progression). J: Quantification of Alizarin red (AR)-positive fibers across ages. K: Quantification of AR staining in 2-, $3-$, and 6-month-old diaphragm sections, confirming the absence of mineralization. Data are expressed as means $\pm \mathrm{SD}$ ( $\mathbf{J}$ and $\mathbf{K}) . n=3$ ( $\mathbf{J}$ and K). ${ }^{* * * *} P<0.0001$.

\section{Age of Onset and Evolution of Ectopic Muscle Mineralization in $m d x$ and $m d x^{\beta g e o}$}

The onset and progression of muscle pathology in the $m d x$ muscle are well documented with cycles of degeneration and regeneration and significant sterile inflammation between 3 and 12 weeks of age, followed by a significant reduction of symptoms from 12 weeks onward. The exception is diaphragm, where the pathology is progressive and thus resembles human disease. ${ }^{30,31}$ Aforementioned exacerbation of ectopic mineralization in $m d x^{\beta g e o}$ led us to assess whether total dystrophin ablation triggers an earlier onset of dystrophic damage with ectopic calcification. To test this hypothesis, AR staining intensities were analyzed in 2- and 4-week-old $m d x$ and $m d x^{\beta g e o}$ diaphragm muscle sections. Twoweek-old muscles were found to be visually devoid of detectable calcifications (Figure 7, A-C), but at 4 weeks, white striations were clearly beginning to form in limb and diaphragm muscles (Figure 7, D-F). Quantification of AR staining in diaphragm sections confirmed first calcified fibers to appear somewhere between 2 and 4 weeks of age but equally in both $m d x$ and $m d x^{\beta g e o}$ animals (Figure 7J). Given the nature of the ectopic calcification, it could be expected to worsen with age, particularly in diaphragms. However, analyses in 3- and 6-month-old mice showed the calcified fibers could no longer be found (Figure 7K). The diaphragm appearance, 

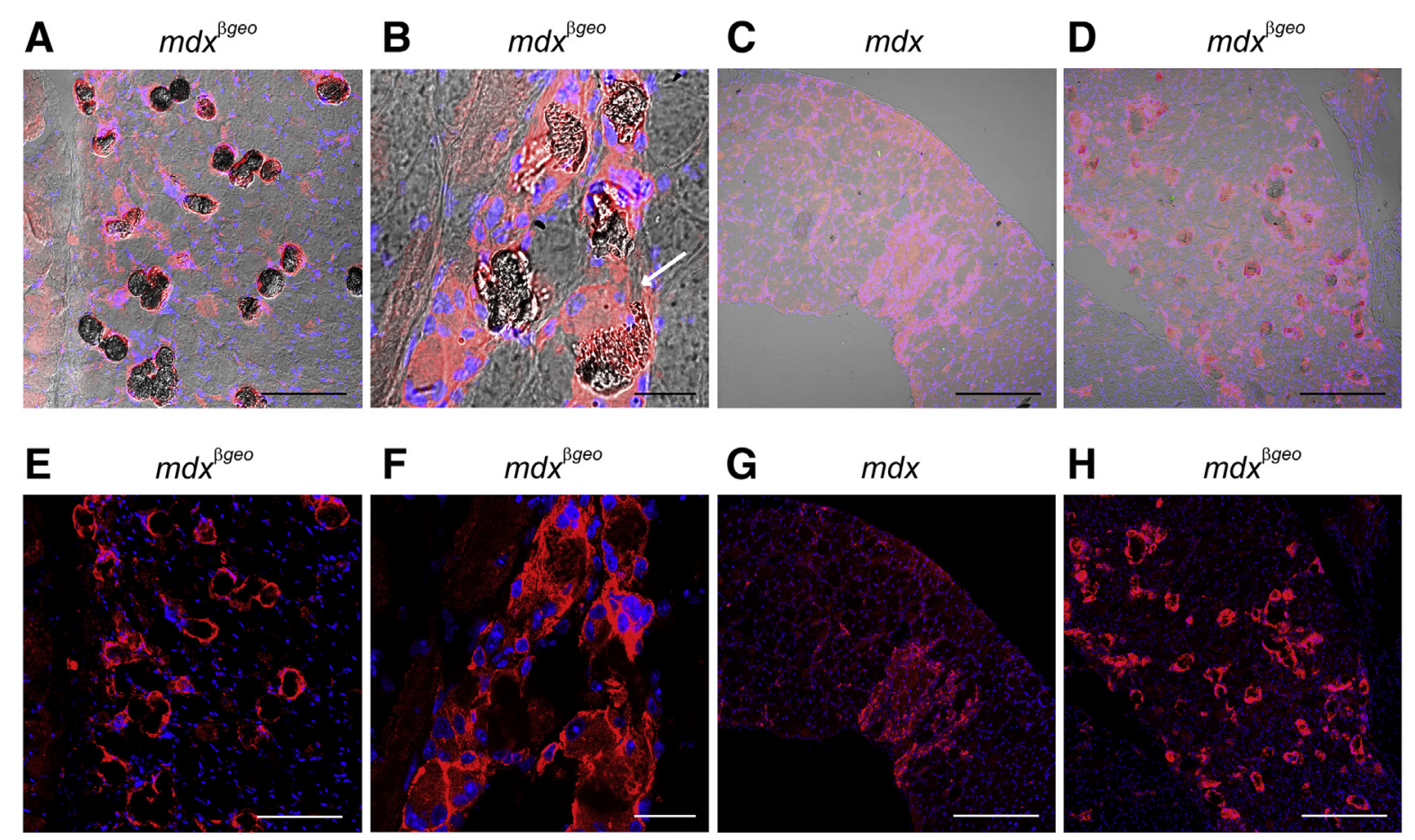

H $m d x^{\beta g e o}$
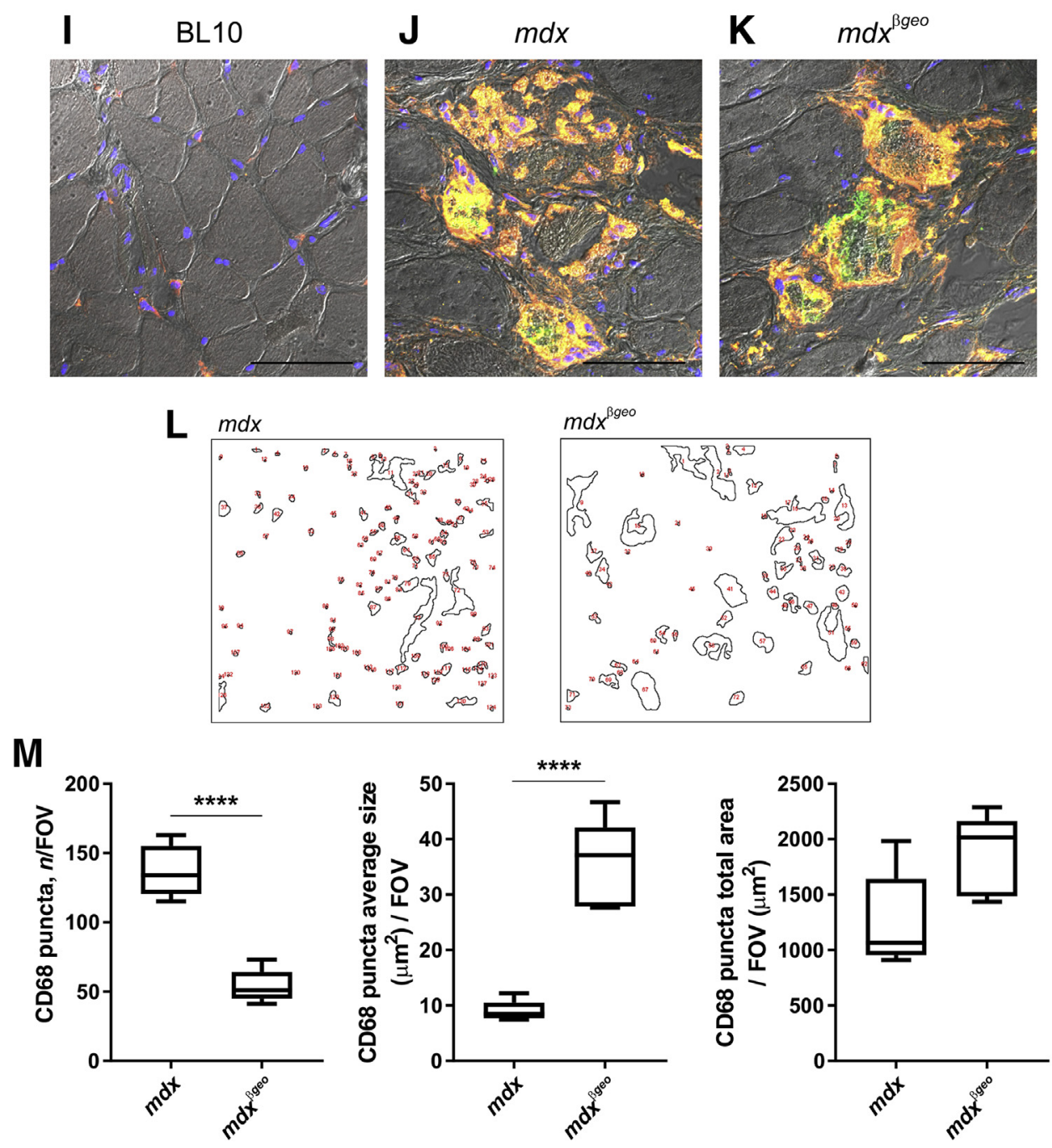
with thickening and opacity (Figure 7, G-I), may be due to ongoing inflammation and emerging fibrosis, which are pathologic hallmarks of 12-month-old diaphragms. Indeed, picrosirius red staining for collagen (Figure 2H) revealed the presence of fibrosis.

\section{Differences in Macrophage Distribution and Association with Mineralized Fibers in $m d x$ versus $m d x^{\beta g e o}$ Diaphragms}

Inflammation is the well-known pathologic hallmark of DMD. It affects muscle regeneration but also degeneration and fibrosis, ${ }^{43,44}$ Of the inflammatory cells found in $m d x$ muscles, macrophages play a significant yet complex role: Their depletion results in the reduction or exacerbation of pathology, depending on the stage of disease..$^{35,44,45}$ The RNA-seq data (Array Express code E-MTAB-7698) identified significant contribution of macrophage genes to the altered inflammatory gene expression profile in mdx muscles (Supplemental Figure S2). Furthermore, a recent study has demonstrated that inorganic phosphate $(\mathrm{Pi})$ can specifically activate macrophages to prevent ectopic calcification. ${ }^{46}$ Given that the evolution of calcified muscle fibers mirrored the onset and cessation of inflammation in $m d x$ muscle, the immune cells in the muscle sections were analyzed. F4/80 staining for macrophages was markedly different in the two dystrophic strains: $m d x$ muscle showed scattered staining with numerous macrophage puncta spread throughout the tissue and only some larger puncta of intense staining (Figure $8, \mathrm{C}$ and $\mathrm{G}$ ). In contrast, $m d x^{\beta g e o}$ muscles displayed large F4/80-positive puncta, which colocalized perfectly with mineralized fibers and appeared almost uniquely and intricately associated with them (Figure 8, A, $\mathrm{B}, \mathrm{D}-\mathrm{F}$, and H). Often, macrophages were tightly associated with what appeared to be partially degraded fibers (Figure 8B). The CD68 and osteopontin staining colocalization in these macrophages indicated their predominantly M1 phenotype (Figure 8, I-K). CD68 macrophage targeting of ectopic calcium deposits was also increased in mdxBgeo, with significantly increased clustering of CD68 (Figure 8, L and $\mathrm{M})$.

In conclusion, total loss of dystrophin expression in the mouse model of DMD specifically exacerbated ectopic myofiber calcification, altered macrophage infiltration, and aggravated subsequent fibrosis.

\section{Discussion}

There is evidence that absence of the full-length (427$\mathrm{kDa}$ ) dystrophin in the fully differentiated myofibers may not necessarily cause the dystrophic phenotype. ${ }^{47,48}$ In contrast, Dp427 has been shown to play a role in satellite cells ${ }^{4,5,9,49,50}$ and there are clear data that a lack of DMD gene expression affects various important functions of myoblasts, including cell proliferation, differentiation, energy metabolism, and signaling. ${ }^{6,8,51}$ These and other findings indicate that dystrophic pathology starts much earlier than has been suggested ${ }^{52}$ and point at the importance of the loss of dystrophin expression in myogenic cells, dysfunction of which determines abnormalities of muscle regeneration and therefore disease progression. Because Dp71 dystrophin has been found in undifferentiated myogenic cells, ${ }^{53}$ we hypothesized that Dmd gene mutations eliminating expression of this isoform may further alter functions of myogenic cells and thus affect the dystrophic phenotype. Therefore, the muscle pathology was compared in the most widely used animal model of DMD-the $m d x$ mouse, lacking full-length isoforms because of a stop mutation in exon $23,{ }^{16}$ against the $m d x^{\beta g e o}$ dystrophinnull mouse. ${ }^{17}$ The latter DMD model is interesting as it has no observed dystrophin-positive revertant fiber clusters $^{45}$ and allows complex phenotypes to be investigated. Notably, mutation hot spots of large deletions and duplications are located in the regions encoding the full-length isoforms. However, small insertions/deletions and point mutations are distributed along the entire gene $^{15}$; and these would affect the full spectrum of dystrophins. However, there are little data evaluating the role of the shorter dystrophin isoforms in muscle.

Our analyses revealed a slightly exacerbated phenotype in $m d x^{\beta g e o}$, especially in older mice. However, these dystrophin-null mice did not show an earlier onset of the dystrophic pathology, which might have been expected given that Dp71 was found expressed in muscle development. ${ }^{17,54}$ The muscle pathology being similar to that in mdx mice was in agreement with the previous study in Cre-

\footnotetext{
Figure 8 Differential macrophage distribution and association with mineralized fibers in $m d x$ and $m d x^{\text {Bgeo }}$ muscles. A: Confocal image showing F4/80 (red) macrophage marker and cell nuclei (blue) staining combined with mineral deposits visualized in bright field in $m d x^{\beta g e o}$ diaphragms. B: Calcified fibers can be seen saturated with macrophages (arrow). C and D: Macrophage distribution differs between $m d x$ and $m d x^{\beta g e o}$ muscles: In $m d x$ diaphragm (C), macrophages can be seen distributed throughout the tissue with some areas of increased infiltration, whereas in $m d x^{\beta g e o}$, macrophages appear to be predominantly associated with calcified fibers (D). E-H: Confocal images of F4/80 staining without bright field, corresponding with $\mathbf{A}$ through $\mathbf{D}$, respectively. I-K: Higher-magnification images showing CD68 (red) marker colocalization with osteopontin (green), indicating the predominantly M1 phenotype of macrophages associated with calcified fibers. L: ImageJ-based (Fiji) quantification of images showing the CD68 staining to localize to fewer (left panel) but larger (right panel) puncta in $m d x^{\beta g e o}$, confirming macrophage clustering at sites of mineralization. M: Significant differences in CD68 puncta number and size are found between $m d x$ and $m d x^{\beta g e o}$ (left and middle panels), but total CD68 intensity in $m d x^{\beta g e o}$ is not found to be significantly different to that of $m d x$ (right panel). Data are expressed as means \pm SD (M). $n=3(\mathbf{M})$. ${ }^{* * * * P<0.0001 . ~ S c a l e ~ b a r s: ~} 250 \mu \mathrm{m}(\mathbf{A}, \mathbf{C}, \mathbf{D}, \mathbf{E}, \mathbf{G}$, and $\mathbf{H}) ; 50 \mu \mathrm{m}(\mathbf{B}$ and $\mathbf{F}) ; 100 \mu \mathrm{m}(\mathbf{I}-\mathbf{K})$. FOV, field of view.
} 
loxP mouse, in which the DMD gene was deleted. ${ }^{55}$ Moreover, no increase in serum creatine kinase levels, indicative of sarcolemma permeability, suggested a different role for this short isoform. Interestingly, the most striking alteration in $m d x^{\beta g e o}$ was the ectopic calcification. Ectopic calcifications have been reported previously in $m d x^{35,56}$ and were found particularly abundant in $m d x /$ Utrophin doubleknockout, $m d x / \delta$-sarcoglycan double-knockout, ${ }^{57}$ and the humanized- $m d x$ mouse models,${ }^{35-38}$ which all present with an exacerbated dystrophic phenotype. Notably, ectopic calcifications are also found in human DMD patients. ${ }^{41}$

One explanation for the different phenotypes could be the protection afforded to the $m d x$ muscle by the revertant, dystrophin-positive fibers. These revertants are thought to arise through splicing events, and they occur at varying frequencies in different muscle groups; approximate average values of $2 \%$ to $7 \%$ in TA and $1 \%$ to $4 \%$ in diaphragm have been reported previously in the $m d x$ mouse. ${ }^{58}$ These fibers are completely absent from $m d x^{\beta g e o}$ muscles. Given that approximately $15 \%$ dystrophin-positive fibers appear sufficient to protect against contraction-induced injury, ${ }^{59}$ revertant fibers could perhaps have some impact.

Another important question is the following: which cells are affected by the lack of short dystrophins? Given that myofibers do not express Dp71, it is likely that these are satellite cells or myoblasts. However, the loss of DMD gene expression in nonmuscle cells cannot be excluded, as indicated by the purinergic phenotype found in DMD patients' lymphoblasts. ${ }^{60}$ Therefore, disease phenotypes in DMD patients with mutation affecting all dystrophins should be reevaluated.

More important, there were significant differences in ectopic calcifications between different muscle groups. This finding may shed new light on the mechanism behind the absence of damage in some and the progressive pathology in other muscle groups that are observed in both DMD patients and mouse models of this disease. This diversity in ectopic calcification was confirmed using a combination of methods, including X-ray microscopy, and a newly developed whole-body optical tissue clearing approach. ${ }^{31}$ The latter method allows us to perform highly reproducible and quantitative assessment of mineralization without a need for highly specialized and expensive equipment, thus permitting such unbiased complete comparisons to be performed in numerous laboratories. Scanning electron microscopy energy-dispersive X-ray spectroscopy electron backscatter analysis of mineralized fibers revealed the presence of calcium and phosphate with a molar ratio of $3: 2$, consistent with tricalcium phosphate $\left[\mathrm{Ca}_{3}\left(\mathrm{PO}_{4}\right)_{2}\right]{ }^{35}$ Nuclear magnetic resonance-based approaches would be more conclusive, but difficulties in obtaining entirely organic-free material without sample damage prevented further investigations. Therefore, although the presence of hydroxyapatite previously described in $m d x$ muscle cannot be ruled out, this material was reported between rather than within fibers, what was documented herein. ${ }^{35}$
Calcified muscles have been linked to increased Pi levels, and serum Pi was found elevated in $m d x$ mice. ${ }^{46}$ Furthermore, dietary Pi intake has been shown to increase muscle calcifications, whereas reduced Pi diet alleviated ectopic calcification in $m d x$ mouse muscle in vivo. ${ }^{45,61}$ In turn, calcium precipitate inhibition with pyrophosphate and bisphosphonate has already shown therapeutic promise in DMD. ${ }^{62-64}$ However, it is not clear whether ectopic calcification is linked to the intracellular calcium accumulation, which resulted in the calcium hypothesis of DMD damage. Assuming that these events are connected, the exacerbated calcification in the dystrophin-null muscle suggests that the calcium influx via permeable sarcolemma solely due to the absence of Dp427 is an insufficient explanation. ${ }^{65}$ Indeed, although elevated calcium levels in muscle fibers are sufficient to induce dystrophic-like changes, ${ }^{66}$ this can occur independently of membrane instability. ${ }^{67}$

Ectopic calcification was also found in $m d x^{\beta g e o}$ hearts but without obvious histologic deterioration compared with $m d x$. These data also agree with observations of cardiac histopathology not being significantly different between $\mathrm{mdx}$ and the Cre-loxP DMD-null mice. ${ }^{12}$ Interestingly, Dp71 in cardiomyocytes is located exclusively in the T-tubules. ${ }^{12}$ Given that most of the calcium enters the cell via Ttubules, absence of Dp71 could affect this function and contribute to ectopic calcification.

Ectopic calcifications in dystrophic muscle appeared at 3 to 4 weeks in both $m d x$ and $m d x^{\beta g e o}$ mice, increasing in number up until 8 to 12 weeks, beyond which calcified myofibers were replaced by fibrosis, which is one of the hallmarks of this disease. Thus, calcification follows the course of $m d x$ pathology in limb muscles and in the diaphragm, one $m d x$ muscle that most closely reproduces disease progression in humans. The timing of calcified fibers being replaced by fibrosis was also approximately week 12 . Therefore, calcification seems to have the same temporal pattern of presentation and resolution in all dystrophic muscle, despite significant differences in intensity across different muscle groups (Figure 5).

The cycles of degeneration and regeneration in $m d x$ muscle are concomitant with immune cell infiltration. These immune cells are attracted by the danger-associated molecular patterns released from damaged muscle, and they play important roles in the pathology: they can contribute to damage but are also involved in clearing the cellular debris and releasing factors facilitating satellite cell activation and therefore promoting muscle regeneration. Moreover, in the chronic disease, inflammation is also linked to fibrosis. ${ }^{32,33}$

The role of macrophages in these processes has been well documented: Pathology in immunocompromised $m d x$ mice that retained functional macrophages was largely unaltered, ${ }^{34}$ whereas macrophage depletion before the onset of muscle damage resulted in significant improvement ${ }^{35,36}$ and total ablation exacerbated the disease. ${ }^{44}$ Furthermore, a recent study demonstrated that inorganic phosphate can activate macrophages to adopt a phenotype allowing them to 
prevent ectopic calcification. ${ }^{37}$ Given that the evolution of calcified muscle fibers mirrored the onset and cessation of inflammatory cell infiltrates in $m d x$ muscle and the important role of macrophages, these cells were analyzed in relation to calcification. The distribution of macrophages was markedly different in $m d x$ versus $m d x^{\beta g e o}$ muscles, with a close colocalization of F4/80 staining puncta with mineralized fibers in the latter. Moreover, the staining often appeared crescent shaped, around what looked like partially digested fibers (Figure 8B). In view that Pi-induced macrophages can evoke anticalcification actions, which are mediated by increased availability of extracellular ATP and pyrophosphate, ${ }^{37}$ the dystrophic muscle would offer ideal conditions for their activation. However, markers expressed on cells in $m d x^{\beta g e o}$ muscles suggested that these had predominantly the M1 phenotype, whereas the Pi-induced macrophages were shown to adopt a phenotype resembling the M2 subtype ${ }^{37}$ Of course, macrophages are known for their ability to change phenotype in response to environmental signals, so functional interplay between populations preventing calcification and eliminating calcified deposits is possible. Manipulating macrophage functions should provide further insight into their role in this process.

Understanding these phenomena may also aid in identifying new therapeutic approaches. Furthermore, ectopic calcification is associated with pathologic outcomes in many human disorders apart from DMD, including osteoarthritis, ${ }^{68}$ atherosclerosis, ${ }^{61}$ sarcoma, ${ }^{69}$ renal disease, ${ }^{70}$ fibrodysplasia ossificans progressiva, ${ }^{71}$ and soft tissue impact trauma, ${ }^{72}$ where macrophage-specific roles are already established.

Given these mouse model data and the correlation of severity of patients' cognitive impairment with the loss of shorter dystrophins both suggest a prominent functional role for these isoforms, comparison of muscle pathology in dystrophin-null patients against those with mutations affecting full-length dystrophins only is clearly warranted. Mouse with selective ablation of Dp71 is not dystrophic ${ }^{54}$ but presents with retinal channel abnormality ${ }^{73}$ early cataract formation, ${ }^{74}$ and vomeronasal nerve defasciculation. ${ }^{75}$ In contrast, transgenic overexpression of Dp71 resulted in more severe muscle disease. ${ }^{76,77}$ Therefore, it may not be the absence of Dp71 but altered expression of dystrophin isoforms at a critical time point or/and at a specific location that causes the pathology.

Understanding the mechanism of this abnormality may contribute to the development of more effective treatments not only for DMD but a range of diseases.

\section{Acknowledgments}

We thank Dr. Slawomir Pikula for advice on mineral deposit analysis, Gianluca Tozzi (Zeiss Global Centre, University of Portsmouth) for help with X-ray micro-computed tomography, and Scott Rodaway for help with in vivo experiments.

\section{Supplemental Data}

Supplemental material for this article can be found at http://doi.org/10.1016/j.ajpath.2019.09.021.

\section{References}

1. Hoffman EP, Fischbeck KH, Brown RH, Johnson M, Medori R, Loire JD, Harris JB, Waterston R, Brooke M, Specht L, Kupsky W, Chamberlain J, Caskey CT, Shapiro F, Kunkel LM: Characterization of dystrophin in muscle-biopsy specimens from patients with $\mathrm{Du}$ chenne's or Becker's muscular dystrophy. N Engl J Med 1988, 318: $1363-1368$

2. Hoffman EP, Brown RH, Kunkel LM: Dystrophin: the protein product of the duchenne muscular dystrophy locus. Cell 1987, 51: 919-928

3. Ahn AH, Kunkel LM: The structural and functional diversity of dystrophin. Nat Genet 1993, 3:283-291

4. Dumont NA, Wang YX, Von Maltzahn J, Pasut A, Bentzinger CF, Brun CE, Rudnicki MA: Dystrophin expression in muscle stem cells regulates their polarity and asymmetric division. Nat Med 2015, 21: $1455-1463$

5. Dumont NA, Wang YX, Rudnicki MA: Intrinsic and extrinsic mechanisms regulating satellite cell function. Development 2015, 142:1572-1581

6. Yeung D, Zablocki K, Lien C-F, Jiang T, Arkle S, Brutkowski W, Brown J, Lochmuller H, Simon J, Barnard EA, Górecki DC: Increased susceptibility to ATP via alteration of P2X receptor function in dystrophic mdx mouse muscle cells. FASEB J 2006, 20: 610-620

7. Young CNJ, Brutkowski W, Lien CF, Arkle S, Lochmüller H, Zabłocki K, Górecki DC: P2X7 purinoceptor alterations in dystrophic mdx mouse muscles: relationship to pathology and potential target for treatment. J Cell Mol Med 2012, 16:1026-1037

8. Young CNJ, Sinadinos A, Lefebvre A, Chan P, Arkle S, Vaudry D, Gorecki DC: A novel mechanism of autophagic cell death in dystrophic muscle regulated by P2RX7 receptor large-pore formation and HSP90. Autophagy 2015, 11:113-130

9. Yablonka-Reuveni Z, Anderson JE: Satellite cells from dystrophic $(\mathrm{Mdx})$ mice display accelerated differentiation in primary cultures and in isolated myofibers. Dev Dyn 2006, 235:203-212

10. Blau HM, Webster C, Pavlath GK: Defective myoblasts identified in Duchenne muscular dystrophy. Proc Natl Acad Sci U S A 1983, 80: 4856-4860

11. Taylor PJ, Betts GA, Maroulis S, Gilissen C, Pedersen RL, Mowat DR, Johnston HM, Buckley MF: Dystrophin gene mutation location and the risk of cognitive impairment in duchenne muscular dystrophy. PLoS One 2010, 5:e8803

12. Masubuchi N, Shidoh Y, Kondo S, Takatoh J, Hanaoka K: Subcellular localization of dystrophin isoforms in cardiomyocytes and phenotypic analysis of dystrophin-deficient mice reveal cardiac myopathy is predominantly caused by a deficiency in full-length dystrophin. Exp Anim 2013, 213:36-47

13. Desguerre I, Christov C, Mayer M, Zeller R, Becane HM, BastujiGarin S, Leturcq F, Chiron C, Chelly J, Gherardi RK: Clinical heterogeneity of Duchenne muscular dystrophy (DMD): definition of sub-phenotypes and predictive criteria by long-term follow-up. PLoS One 2009, 4:e4347

14. Aartsma-Rus A, Ginjaar IB, Bushby K: The importance of genetic diagnosis for Duchenne muscular dystrophy. J Med Genet 2016, 53: $145-151$

15. Juan-Mateu J, Gonzalez-Quereda L, Rodriguez MJ, Baena M, Verdura E, Nascimento A, Ortez C, Baiget M, Gallano P: DMD mutations in 576 dystrophinopathy families: a step forward in genotype-phenotype correlations. PLoS One 2015, 10:1-21 
16. Bulfield G, Siller WG, Wight PA, Moore KJ: X chromosome-linked muscular dystrophy $(\mathrm{mdx})$ in the mouse. Proc Natl Acad Sci U S A 1984, 81:1189-1192

17. Wertz K, Füchtbauer EM: Dmd(mdx- $\beta$ geo): a new allele for the mouse dystrophin gene. Dev Dyn 1998, 212:229-241

18. Petkov PM, Ding Y, Cassell MA, Zhang W, Wagner G, Sargent EE, Asquith S, Crew V, Johnson KA, Robinson P, Scott VE, Wiles MV: An efficient SNP system for mouse genome scanning and elucidating strain relationships. Genome Res 2004, 14:1806-1811

19. McGreevy JW, Hakim CH, McIntosh MA, Duan D: Animal models of Duchenne muscular dystrophy: from basic mechanisms to gene therapy. Dis Model Mech 2015, 8:195-213

20. Al-Khalidi R, Panicucci C, Cox P, Chira N, Róg J, Young CNJ, McGeehan RE, Ambati K, Ambati J, Zabłocki K, Gazzerro E, Arkle S, Bruno C, Górecki DC: Zidovudine ameliorates pathology in the mouse model of Duchenne muscular dystrophy via P2RX7 purinoceptor antagonism. Acta Neuropathol Commun 2018, 6:27

21. Dobin A, Davis CA, Schlesinger F, Drenkow J, Zaleski C, Jha S, Batut P, Chaisson M, Gingeras TR: STAR: ultrafast universal RNAseq aligner. Bioinformatics 2013, 29:15-21

22. Love MI, Huber W, Anders S: Moderated estimation of fold change and dispersion for RNA-seq data with DESeq2. Genome Biol 2014, 15:550-571

23. R Core Team: R: A language and environment for statistical computing. Vienna, Austria: R Foundation for Statistical Computing, 2017

24. Lawrence $M$, Huber W, Pagès $H$, Aboyoun $P$, Carlson M, Gentleman R, Morgan MT, Carey VJ: Software for computing and annotating genomic ranges. PLoS Comput Biol 2013, 9:1-10

25. Hochberg B: Controlling the false discovery rate: a practical and powerful approach to multiple testing. J R Stat Soc 1995, 57: 289-300

26. Abràmoff $\mathrm{MD}$, Magalhães $\mathrm{PJ}$, Ram SJ: Image processing with imageJ. Biophotonics Int 2004, 11:36-42

27. Bozycki L, Łukasiewicz K, Matryba P, Pikula S: Whole-body clearing, staining and screening of calcium deposits in the mdx mouse model of Duchenne muscular dystrophy. Skelet Muscle 2018, 8:21

28. Susaki EA, Tainaka K, Perrin D, Kishino F, Tawara T, Watanabe TM, Yokoyama C, Onoe H, Eguchi M, Yamaguchi S, Abe T, Kiyonari H, Shimizu Y, Miyawaki A, Yokota H, Ueda HR: Whole-brain imaging with single-cell resolution using chemical cocktails and computational analysis. Cell 2014, 157:726-739

29. Sinadinos A, Young CNJ, Al-Khalidi R, Teti A, Kalinski P, Mohamad S, Floriot L, Henry T, Tozzi G, Jiang T, Wurtz O, Lefebvre A, Shugay M, Tong J, Vaudry D, Arkle S, DoRego JC, Górecki DC: P2RX7 purinoceptor: a therapeutic target for ameliorating the symptoms of duchenne muscular dystrophy. PLoS Med $2015,12: 1-33$

30. Suelves M, Vidal B, Serrano AL, Tjwa M, Roma J, LópezAlemany R, Luttun A, De Lagrán MM, Díaz MÀ, Jardí M, Roig M, Dierssen M, Dewerchin M, Carmeliet P, Muñoz-Cánoves P: uPA deficiency exacerbates muscular dystrophy in MDX mice. J Cell Biol 2007, 178:1039-1051

31. Yucel N, Chang AC, Day JW, Rosenthal N, Blau HM: Humanizing the mdx mouse model of DMD: the long and the short of it. NPJ Regen Med 2018, 3:4

32. Stedman HH, Sweeney HL, Shrager JB, Maguire HC, Panettieri RA, Petrof B, Narusawa M, Leferovich JM, Sladky JT, Kelly AM: The $\mathrm{mdx}$ mouse diaphragm reproduces the degenerative changes of Duchenne muscular dystrophy. Nature 1991, 352:536-539

33. Aartsma-Rus A, van Putten M: Assessing functional performance in the mdx mouse model. J Vis Exp 2014, 85:e51303

34. Briguet A, Courdier-Fruh I, Foster M, Meier T, Magyar JP: Histological parameters for the quantitative assessment of muscular dystrophy in the mdx-mouse. Neuromuscul Disord 2004, 14:675-682
35. Kikkawa N, Ohno T, Nagata Y, Shiozuka M, Kogure T, Matsuda R: Ectopic calcification is caused by elevated levels of serum inorganic phosphate in mdx mice. Cell Struct Funct 2009, 34:77-88

36. Sohn J, Lu A, Tang Y, Wang B, Huard J: Activation of nonmyogenic mesenchymal stem cells during the disease progression in dystrophic dystrophin/utrophin knockout mice. Hum Mol Genet $2015,24: 3814-3829$

37. Isaac C, Wright A, Usas A, Li H, Tang Y, Mu X, Greco N, Dong Q, Vo N, Kang J, Wang B, Huard J: Dystrophin and utrophin "double knockout" dystrophic mice exhibit a spectrum of degenerative musculoskeletal abnormalities. J Orthop Res 2014, 31:343-349

38. Wada E, Yoshida M, Kojima Y, Nonaka I, Ohashi K, Nagata Y, Shiozuka M, Date M, Higashi T, Nishino I, Matsuda R: Dietary phosphorus overload aggravates the phenotype of the dystrophindeficient mdx mouse. Am J Pathol 2014, 184:3094-3104

39. Barthélémy I, Uriarte A, Drougard C, Unterfinger Y, Thibaud JL, Blot S: Effects of an immunosuppressive treatment in the GRMD dog model of Duchenne muscular dystrophy. PLoS One 2012, 7:e48478

40. Liu JMK, Okamura CS, Bogan DJ, Bogan JR, Childers MK, Kornegay JN: Effects of prednisone in canine muscular dystrophy. Muscle Nerve 2004, 30:767-773

41. Larcher T, Lafoux A, Tesson L, Remy S, Thepenier V, François V, Le Guiner C, Goubin H, Dutilleul M, Guigand L, Toumaniantz G, De Cian A, Boix C, Renaud J-B, Cherel Y, Giovannangeli C, Concordet J-P, Anegon I, Huchet C: Characterization of dystrophin deficient rats: a new model for Duchenne muscular dystrophy. PLoS One 2014, 9:e110371

42. Vallet-Regí M: Ceramics for medical applications. J Chem Soc Dalton Trans 2001, 2:97-108

43. Villalta SA, Rosenberg AS, Bluestone JA: The immune system in Duchenne muscular dystrophy: friend or foe. Rare Dis 2015, 3: e1010966

44. Villalta SA, Nguyen HX, Deng B, Gotoh T, Tidbal JG: Shifts in macrophage phenotypes and macrophage competition for arginine metabolism affect the severity of muscle pathology in muscular dystrophy. Hum Mol Genet 2009, 18:482-496

45. Farini A, Meregalli M, Belicchi M, Battistelli M, Parolini D, D'Antona G, Gavina M, Ottoboni L, Constantin G, Bottinelli R, Torrente Y: T and B lymphocyte depletion has a marked effect on the fibrosis of dystrophic skeletal muscles in the scid/mdx mouse. J Pathol 2007, 213:229-238

46. Villa-Bellosta R, Hamczyk MR, Andrés V: Novel phosphateactivated macrophages prevent ectopic calcification by increasing extracellular ATP and pyrophosphate. PLoS One 2017, 12:e0174998

47. Seno MMG, Graham IR, Athanasopoulos T, Trollet C, Pohlschmidt M, Crompton MR, Dickson G: RNAi-mediated knockdown of dystrophin expression in adult mice does not lead to overt muscular dystrophy pathology. Hum Mol Genet 2008, 17:2622

48. Rader EP, Turk R, Willer T, Beltrán D, Inamori K, Peterson TA, Engle J, Prouty S, Matsumura K, Saito F, Anderson ME, Campbell KP: Role of dystroglycan in limiting contraction-induced injury to the sarcomeric cytoskeleton of mature skeletal muscle. Proc Natl Acad Sci U S A 2016, 113:10992-10997

49. Xie X, Tsai SY, Tsai MJ: COUP-TFII regulates satellite cell function and muscular dystrophy. J Clin Invest 2016, 126:3929-3941

50. Alexakis C, Partridge T, Bou-Gharios G: Implication of the satellite cell in dystrophic muscle fibrosis: a self-perpetuating mechanism of collagen overproduction. Am J Physiol Cell Physiol 2007, 293:661-669

51. Young CNJ, Chira N, Róg J, Al-Khalidi R, Benard M, Galas L, Chan P, Vaudry D, Zabłocki K, Górecki DC: Sustained activation of P2X7 induces MMP-2-evoked cleavage and functional purinoceptor inhibition. J Mol Cell Biol 2017, 10:229-242

52. Merrick D, Stadler LKJ, Larner D, Smith J: Muscular dystrophy begins early in embryonic development deriving from stem cell loss and disrupted skeletal muscle formation. Dis Model Mech 2009, 2 : $374-388$ 
53. Howard PL, Dally GY, Ditta SD, Austin RC, Worton RG, Klamut HJ, Ray PN: Dystrophin isoforms Dp71 and Dp427 have distinct roles in myogenic cells. Muscle Nerve 1999, 22:16-27

54. Sarig R, Mezger-Lallemand V, Gitelman I, Davis C, Fuchs O, Yaffe D, Nudel U: Targeted inactivation of Dp71, the major nonmuscle product of the DMD gene: differential activity of the Dp71 promoter during development. Hum Mol Genet 1999, 8:1-10

55. Kudoh H, Ikeda H, Kakitani M, Ueda A, Hayasaka M, Tomizuka K, Hanaoka K: A new model mouse for Duchenne muscular dystrophy produced by $2.4 \mathrm{Mb}$ deletion of dystrophin gene using Cre-loxP recombination system. Biochem Biophys Res Commun 2005, 328:507-516

56. Geissinger HD, Prasada Rao PVV, McDonald-Taylor CK: "mdx" Mouse myopathy: histopathological, morphometric and histochemical observations on young mice. J Comp Pathol 1990, 102:249-263

57. Li D, Long C, Yue Y, Duan D: Sub-physiological sarcoglycan expression contributes to compensatory muscle protection in $\mathrm{mdx}$ mice. Hum Mol Genet 2009, 18:1209-1220

58. Pigozzo SR, Da Re L, Romualdi C, Mazzara PG, Galletta E, Fletcher S, Wilton SD, Vitiello L: Revertant fibers in the mdx murine model of Duchenne muscular dystrophy: an age- and muscle-related reappraisal. PLoS One 2013, 8:1-6

59. Godfrey C, Muses S, McClorey G, Wells KE, Coursindel T, Terry RL, Betts C, Hammond S, O'Donovan L, Hildyard J, El Andaloussi S, Gait MJ, Wood MJ, Wells DJ: How much dystrophin is enough: the physiological consequences of different levels of dystrophin in the mdx mouse. Hum Mol Genet 2015, 24:4225-4237

60. Ferrari D, Munerati M, Melchiorri L, Hanau S, Di Virgilio F, Baricordi OR: Responses to extracellular ATP of lymphoblastoid cell lines from Duchenne muscular dystrophy patients. Am J Physiol 1994, 267:886-892

61. Chinetti-Gbaguidi G, Colin S, Staels B: Macrophage subsets in atherosclerosis. Nat Rev Cardiol 2015, 12:10-17

62. Bauer C, Le Saux O, Pomozi V, Aherrahrou R, Kriesen R, Stölting S, Liebers A, Kessler T, Schunkert H, Erdmann J, Aherrahrou Z: Etidronate prevents dystrophic cardiac calcification by inhibiting macrophage aggregation. Sci Rep 2018, 8:5812

63. Finckh A, Mc Carthy GM, Madigan A, Van Linthoudt D, Weber M, Neto D, Rappoport G, Blumhardt S, Kyburz D, Guerne P-A: Methotrexate in chronic-recurrent calcium pyrophosphate deposition disease: no significant effect in a randomized crossover trial. Arthritis Res Ther 2014, 16:458

64. Pomozi V, Brampton C, van de Wetering K, Zoll J, Calio B, Pham K, Owens JB, Marh J, Moisyadi S, Váradi A, Martin L, Bauer C, Erdmann J, Aherrahrou Z, Le Saux O: Pyrophosphate supplementation prevents chronic and acute calcification in ABCC6-deficient mice. Am J Pathol 2017, 187:1258-1272
65. Cullen SP, Kearney CJ, Clancy DM, Martin SJ: Diverse activators of the NLRP3 inflammasome promote IL-1 $\beta$ secretion by triggering necrosis. Cell Rep 2015, 11:1535-1548

66. Burr AR, Molkentin JD: Genetic evidence in the mouse solidifies the calcium hypothesis of myofiber death in muscular dystrophy. Cell Death Differ 2015, 22:1402-1412

67. Millay DP, Goonasekera SA, Sargent MA, Maillet M, Aronow BJ, Molkentin JD: Calcium influx is sufficient to induce muscular dystrophy through a TRPC-dependent mechanism. Proc Natl Acad Sci U S A 2009, 106:19023-19028

68. Hawellek T, Hubert J, Hischke S, Vettorazzi E, Wegscheider K, Bertrand J, Pap T, Krause M, Püschel K, Rüther W, Niemeier A: Articular cartilage calcification of the humeral head is highly prevalent and associated with osteoarthritis in the general population. J Orthop Res 2016, 34:1984-1990

69. Przybyl J, Kowalewska M, Quattrone A, Dewaele B, Vanspauwen V, Varma S, Vennam S, Newman AM, Swierniak M, BakułaZalewska E, Siedlecki JA, Bidzinski M, Cools J, van de Rijn M, Debiec-Rychter M: Macrophage infiltration and genetic landscape of undifferentiated uterine sarcomas. JCI Insight 2017, 2:e94033

70. Jablonski KL, Chonchol M: Vascular calcification in end-stage renal disease. Hemodial Int 2013, 17 Suppl 1:S17-S21

71. Regard JB, Malhotra D, Gvozdenovic-Jeremic J, Josey M, Chen M, Weinstein LS, Lu J, Shore EM, Kaplan FS, Yang Y: Activation of hedgehog signaling by loss of GNAS causes heterotopic ossification. Nat Med 2013, 19:1505-1512

72. King JB: Post-traumatic ectopic calcification in the muscles of athletes: a review. Br J Sports Med 1998, 32:287-290

73. Dalloz C, Sarig R, Fort P, Yaffe D, Bordais A, Pannicke T, Grosche J, Mornet D, Reichenbach A, Sahel J, Nudel U, Rendon A: Targeted inactivation of dystrophin gene product Dp71: phenotypic impact in mouse retina. Hum Mol Genet 2003, 12:1543-1554

74. Fort PE, Darche M, Sahel JA, Rendon A, Tadayoni R: Lack of dystrophin protein Dp71 results in progressive cataract formation due to loss of fiber cell organization. Mol Vis 2014, 4:1480-1490

75. Takatoh J, Kudoh H, Kondo S, Hanaoka K: Loss of short dystrophin isoform Dp71 in olfactory ensheathing cells causes vomeronasal nerve defasciculation in mouse olfactory system. Exp Neurol 2008, 213:36-47

76. Cox GA, Sunada Y, Campbell KP, Chamberlain JS: Dp71 can restore the dystrophin-associated glycoprotein complex in muscle but fails to prevent dystrophy. Nat Genet 1994, 8:333-339

77. Greenberg DS, Sunada Y, Campbell KP, Yaffe D, Nudel U: Exogenous Dp71 restores the levels of dystrophin associated proteins but does not alleviate muscle damage in mdx mice. Nat Genet 1994, 8: $340-344$ 